\title{
Loneliness and the Big Five Personality Traits: A Meta-Analysis
}

Susanne Buecker ${ }^{1}$, Marlies Maes², Jaap J. A. Denissen ${ }^{3}$, and Maike Luhmann ${ }^{1}$

${ }^{1}$ Ruhr-Universität Bochum, Germany, ${ }^{2} \mathrm{KU}$ Leuven, Belgium, ${ }^{3}$ Tilburg University, the Netherlands

Final accepted version, 30 Nov 2019 (in press, European Journal of Personality).

DOI: $10.1002 /$ per.2229

This preprint may differ slightly from the final, copy-edited version of record. 
Author Note

Please note that we registered a preregistration of this meta-analysis via the Open Science Framework (https://osf.io/73cnx/?view_only=b0574814c94f4dc59e1573b59c697a33). In addition, we provide all raw data necessary to reproduce our results and provide $\mathrm{R}$ scripts for all data analyses reported in this manuscript (https://osf.io/gt7qa/).

Correspondence concerning this article should be addressed to Susanne Buecker, Ruhr University Bochum, Germany, Department of Psychology, Universitätsstraße 150, D-44780

Bochum, E-mail: susanne.buecker@rub.de 


\begin{abstract}
This preregistered meta-analysis $(k=113$, total $n=93,668)$ addressed how the Big Five dimensions of personality (extraversion, agreeableness, conscientiousness, neuroticism, and openness) are related to loneliness. Robust variance estimation accounting for the dependency of effect sizes was used to compute meta-analytic bivariate correlations between loneliness and personality. Extraversion $(r=-.370)$, agreeableness $(r=-.243)$, conscientiousness $(r=-.202)$, and openness $(r=-.107)$ were negatively related to loneliness. Neuroticism $(r=.358)$ was positively related to loneliness. These associations differed meaningfully in strength depending on how loneliness was assessed. Additionally, meta-analytic structural equation modelling was used to investigate the unique association between each personality trait and loneliness while controlling for the other four personality traits. All personality traits except openness remained statistically significantly associated with loneliness when controlling for the other personality traits. Our results show the importance of stable personality factors in explaining individual differences in loneliness.
\end{abstract}

Keywords: loneliness, perceived social isolation, personality, Big Five, meta-analysis 
Loneliness and the Big Five Personality Traits: A Meta-Analysis

The need for social connection and belonging is present in all humans (Barrick, Mount, \& Li, 2013; Baumeister \& Leary, 1995). However, there are individual differences in the degree of desired social connection and in affective reactions to the loss of social bonds (J. T. Cacioppo \& Patrick, 2008; Dufner, Arslan, Hagemeyer, Schönbrodt, \& Denissen, 2015). In most social environments, one could find someone like Thomas, a reserved and rather introverted man in his late thirties who worries a lot about daily hassles, is often nervous and emotionally unstable. One could also find someone like David, an outgoing and energetic man of the same age as Thomas. He would describe himself as someone who needs social connection through group membership and is talkative. Although both individuals share similar objective environmental characteristics, Thomas reports feeling lonely relatively often, whereas David experiences this feeling rather rarely. A central difference between both individuals is their personality, which can be used to predict their risk for feeling lonely.

Despite a growing interest in interindividual differences in loneliness over the last years, surprisingly few studies have directly focused on the association between loneliness and broader personality traits (Abdellaoui et al., 2019; Cheng \& Furnham, 2002; Mund \& Neyer, 2016, 2018; Teppers et al., 2013). Fortunately, even studies that were not initially focused on the association between loneliness and personality often collected data on both sets of constructs. The present meta-analysis taps into this underused source of data and provides the first comprehensive account of how loneliness and broader personality traits are related and how robust these relations are across different types of samples, loneliness measures, and other factors. To allow reproducibility of our meta-analytic results, we followed the Meta-Analysis Reporting Standards 
(MARS). The preregistration of this meta-analysis, along with the data and $\mathrm{R}$ code to reproduce our results, are available on the Open Science Framework (OSF): https://osf.io/gt7qa/.

\section{Loneliness}

Loneliness is described as the subjective perception of a discrepancy between the desired and the actual social relationships in terms of companionship, connectedness, or intimacy (De Jong Gierveld \& van Tilburg, 2006; Hawkley \& Cacioppo, 2010). Unidimensional conceptualizations of loneliness assume one overall loneliness dimension whereas multidimensional conceptualizations of loneliness differentiate between sub-dimensions or facets of loneliness. There is agreement on two dimensions of loneliness among loneliness researchers. Emotional loneliness (Weiss, 1973) is described as the perceived absence of a close attachment figure, such as a romantic partner (S. Cacioppo, Grippo, London, Goossens, \& Cacioppo, 2015; Weiss, 1973). Social loneliness is described as the perceived absence of a broader social network and quality friendships as well as the lack of the feeling to belong (S. Cacioppo et al., 2015; Weiss, 1973). Emotional and social loneliness are associated with different affective reactions, but can be characterized by a shared core of experiences (DiTommaso \& Spinner, 1997; Russell, Cutrona, Rose, \& Yurko, 1984). Both emotional and social loneliness have in common that they involve a mismatch between desired and actual social relationships. Because they tap into the same underlying need, both dimensions of loneliness can be aggregated into an overall loneliness score.

\section{Personality and Loneliness}

Personality describes individuals' relatively enduring patterns of cognition, emotion, and behavior that distinguish one person from another (Roberts, Wood, \& Caspi, 2008). One highly influential model describing personality structure is the Five-Factor-Model (FFM) (McCrae \& 
Costa, 2008). The FFM encompasses the traits extraversion, agreeableness, conscientiousness, neuroticism, and openness to experience (McCrae \& Costa, 2008).

Meta-analytically investigating the relation between personality traits and loneliness is important for at least three reasons. First, a rigorous test of the relations between personality traits and loneliness could correct for biases that produce the illusion of inconsistent findings among single studies (Borenstein, Hedges, Higgins, \& Rothstein, 2009) and test moderators of these relations that are not yet covered in one single study but can be examined by synthesizing all available studies. Second, the FFM provides a nomological network that helps explain similarities and differences among psychological constructs. Embedding loneliness in the FMM will thus help avoiding jingle-jangle fallacies (i.e., different labels used for the same construct). This is particularly relevant because it has been suggested that loneliness has trait-like characteristic and might be conceptualized as part of personality (Mund, Freuding, Möbius, Horn, \& Neyer, 2019). Third, understanding whether and how personality traits and loneliness are interwoven will allow the identification of subgroups of individuals that might be at risk of developing loneliness. Therefore, the findings of this meta-analysis can inform future research on loneliness from a personality psychological perspective by identifying personality traits as risk or protective factors for the development of loneliness.

Below, we briefly outline the interplay between personality and loneliness separately for each personality trait. Although there are different plausible mechanisms suggesting an effect of broader personality traits on loneliness, the causal direction of this link is not yet clear. Mund and Neyer (2018), for example, found that loneliness predicted all Big Five traits except openness five years later. The present meta-analysis focuses on correlations, leaving it an open question 
whether there are uni- or bi-directional effects. However, we discuss possible bi-directional effects between loneliness and personality further down.

\section{Extraversion and Loneliness}

Although direct evidence is sparse, the few existing studies that explicitly investigated the association between loneliness and extraversion consistently found a negative association (Hensley et al., 2012; Saklofske \& Yackulic, 1989; Stokes, 1985; Teppers et al., 2013; Vanhalst et al., 2012). Extraverted individuals have a preference for engaging in and enjoying social interactions (Costa \& McCrae, 1980; John, Robins, \& Pervin, 2008). Extraverted individuals might therefore actively seek out others for interaction, and ultimately befriend them (Selfhout et al., 2010). Extraversion predicts greater participation in social activities (Lucas, Le, \& Dyrenforth, 2008), is linked to higher social status (Anderson, John, Keltner, \& Kring, 2001), greater social networks (Stokes, 1985), and to more perceived support from peers (Asendorpf \& Van Aken, 2003). Extraversion was identified as a main predictor of sociable behavior in various studies (Breil et al., 2019; Eaton \& Funder, 2003; Fleeson \& Gallagher, 2009; Sherman, Rauthmann, Brown, Serfass, \& Jones, 2015). Further, individuals high in extraversion are more likely to engage in everyday life situations perceived as high in sociality (Horstmann, Rauthmann, Sherman, \& Ziegler, 2019; Sherman et al., 2015). Additionally, extraversion is associated with other positive interpersonal outcomes such as likeability and popularity (Mervielde \& De Fruyt, 2000; Nikitin \& Freund, 2015; van der Linden, Scholte, Cillessen, Nijenhuis, \& Segers, 2010), which might affect loneliness. Moreover, the enthusiastic behavior of an extraverted individual might evoke a positive reaction in similar others (van Zalk \& Denissen, 2015) - they enjoy being in one another's company. Based on the above stated literature, we derived the following hypothesis. 
Hypothesis 1: Extraversion is negatively related to loneliness.

\section{Agreeableness and Loneliness}

The few existing studies that directly investigated the association between loneliness and agreeableness consistently found a negative relation (Hensley et al., 2012; Saklofske \& Yackulic, 1989; Stokes, 1985; Teppers et al., 2013; Vanhalst et al., 2012). Agreeableness is described by motives for maintaining positive and smooth interactions with others and minimizing social conflict (Jensen-Campbell et al., 2002; Tobin, Graziano, Vanman, \& Tassinary, 2000). Like extraversion, agreeableness is associated with positive interpersonal outcomes such as likeability and popularity (Mervielde \& De Fruyt, 2000; Nikitin \& Freund, 2015; van der Linden et al., 2010), and with being selected as friend (Selfhout et al., 2010). Agreeable adolescents report having fewer interpersonal conflicts (Asendorpf \& Wilpers, 1998) and are more empathic than less agreeable individuals (Song \& Shi, 2017). Empathy, in turn, shows a negative relation with loneliness, such that individuals scoring high on empathy have been found to report lower loneliness (Beadle, Keady, Brown, Tranel, \& Paradiso, 2012). The warm, friendly, and considerate attitude of agreeable individuals in social situations might explain why agreeableness and loneliness are negatively related. Taken together, the literature therefore suggests that agreeableness and loneliness might be negatively related.

Hypothesis 2: Agreeableness is negatively related to loneliness.

\section{Conscientiousness and Loneliness}

The few existing studies that directly investigated the association between loneliness and conscientiousness were consistent in effect size (rather small), but inconsistent in terms of statistical significance and the direction of the effect. Some studies found positive relations (e.g., $r=.07$; Teppers et al., 2013) whereas others found negative relations (e.g., $r=-.07$; Mund \& 
Neyer, 2018) or no significant relation (e.g., $r=.00$; Vanhalst et al., 2012) with loneliness. One might speculate that the responsible and reliable behavior of highly conscientious individuals includes maintaining regular contact with friends and family. With respect to indirect evidence, conscientiousness is indeed predictive of the frequency and the intensity of contact with family members, but not of the frequency and intensity of contact with friends (Asendorpf \& Wilpers, 1998). Although the empirical evidence is mixed, there are theoretical grounds to assume a negative relation between loneliness and conscientiousness.

Hypothesis 3: Conscientiousness is negatively related to loneliness.

\section{Neuroticism and Loneliness}

Although evidence is sparse, the few existing studies that directly investigated the association between loneliness and neuroticism consistently found a positive relation (Hensley et al., 2012; Saklofske \& Yackulic, 1989; Stokes, 1985; Teppers et al., 2013; Vanhalst et al., 2012). Concerning indirect evidence, neuroticism is related to a heightened reactivity to social stressors (Zautra, Affleck, Tennen, Reich, \& Davis, 2005). Moreover, highly neurotic individuals are more sensitive to cues of social rejection (Denissen \& Penke, 2008), which may result in feelings of loneliness. Neuroticism has been linked to dysfunctional interpersonal behavior leading to lower relationship satisfaction (Vater \& Schröder-Abé, 2015). Additionally, individuals scoring low on neuroticism (i.e., emotionally stable) are described as more likeable by their peers (van der Linden et al., 2010), which can result in lower loneliness. Note that whereas related constructs of loneliness such as depression or anxiety are facets of trait neuroticism and therefore have some construct overlap with each other (DeYoung, Quilty, \& Peterson, 2007), loneliness commonly is not understood as such a facet of one of the personality traits. Taken together, available studies suggest that neuroticism and loneliness are positively correlated. 
Hypothesis 4: Neuroticism is positively related to loneliness.

\section{Openness and Loneliness}

The few existing studies that directly investigated the association between loneliness and openness were consistent in effect size (rather small), but inconsistent in terms of statistical significance. Some previous studies found negative relations (e.g., $r=-.11$; Vanhalst et al., 2012) whereas other found no significant relation (e.g., $r=-.04$; Teppers et al., 2013) with loneliness. Compared to the other personality traits, openness has fewer social consequences and is often described as an intrapsychic rather than an interpersonal dimension (McCrae, 1996). However, there might be a weak tendency for individuals higher in openness to evoke more positive reactions in others or to seek out new situations that might also include social contacts. Therefore, it seems reasonable to assume that loneliness is weakly negatively or not at all significantly related to loneliness.

Hypothesis 5: Openness is either weakly negatively related to loneliness or not at all significantly related to loneliness.

\section{Multivariate Relations Between Personality and Loneliness}

To our best knowledge, very few studies investigated the unique relation between loneliness and personality when controlling for the other four personality traits. Controlling for other personality traits is important as multivariate associations are less influenced by biases such as a general response bias. Even though the Big Five are thought to be orthogonal factors, a meta-analysis showed that there are statistically significant intercorrelations among the Big Five, ranging from $r=.14$ for openness and agreeableness to $r=-.32$ for conscientiousness and neuroticism (van der Linden et al., 2010). In a recent study, Abdellaoui et al. (2018) found that only neuroticism was statistically significantly associated with loneliness when all Big Five 
personality traits were entered as simultaneous predictors. In contrast, Teppers et al. (2013) found that neuroticism was not a significant predictor of loneliness when controlling for the other four personality traits; and extraversion showed the strongest relation to loneliness (note that also cognitive-personality styles were included in the model). However, it is not yet known whether these findings replicate. Therefore, we investigated whether and how the unique relation of each Big Five personality trait and loneliness differs when controlling for the other four personality traits. Based on the available studies, we formulated the following hypothesis.

Hypothesis 6: Neuroticism and extraversion show the strongest associations with loneliness when controlling for the other personality traits in a multivariate model.

\section{Moderators of the Relation Between Loneliness and Personality}

We examined average age, the loneliness scale, and the dimension of loneliness as moderators of the relationship between loneliness and personality. Age might affect the strength of the relation between personality and loneliness. Indeed, one study that examined this hypothesis explicitly (Butkovic, Brkovic, \& Bratko, 2012) found that the relation between extraversion and loneliness was stronger in adolescents $(r=-.70)$ than in older adults $(r=-.52)$. For agreeableness and conscientiousness, in contrast, the relationship was stronger for older adults than for adolescents, and it did not differ between adolescents and older adults with respect to neuroticism (Butkovic et al., 2012). The relationship between extraversion and loneliness might be moderated by age because at a younger age, finding friends is more dependent on the outgoing nature of a person whereas at an older age, other competencies and experiences might be more important (Lehmann, Denissen, Allemand, \& Penke, 2013; Wrzus, Wagner, \& Riediger, 2016). We therefore included average sample age as a potential moderator in all analyses, but a-priori specified a directed hypothesis for extraversion only. 
Hypothesis 7: The negative relation between extraversion and loneliness is stronger for adolescents than for adults.

Loneliness scale was examined as an exploratory moderator to test whether the relation between loneliness and personality is affected by the questionnaire used to assess loneliness. We categorized the loneliness scales into three groups. The first two of these categories represented the UCLA Loneliness Scale (Russell, 1996) and the De Jong Gierveld Loneliness Scale (DJGLS) (De Jong Gierveld \& van Tilburg, 2006), both of which are used most frequently in research on loneliness. Although loneliness scores from the UCLA Loneliness Scale and the DJG-LS are highly correlated (e.g., $r>$.80; Grygiel, Humenny, Rebisz, Świtaj, \& Sikorska, 2013; Maes, Vanhalst, Van den Noortgate, \& Goossens, 2017), they might capture distinct aspects of loneliness. From a psychometric perspective, it seems interesting to investigate whether the two most widely used measures (i.e., the UCLA Loneliness Scale and the DJG-LS; De Jong Gierveld \& Van Tilburg, 2006; Russell et al., 1984) capture the same construct, which would lead to comparable associations with external criteria such as the Big Five personality traits. The third category included all loneliness scales that have been used only a few times (e.g., Social and Emotional Loneliness Scale for Adults (SELSA; DiTommaso \& Spinner, 1993) or single item measures of loneliness.

Finally, the relation between personality and loneliness might differ among different dimensions of loneliness such as overall loneliness, emotional loneliness, or social loneliness. This moderator could only be tested for studies using multidimensional loneliness measures that distinguished among different dimensions of loneliness. Extraversion might be more strongly related to social loneliness than emotional loneliness because social loneliness is described as the perceived absence of an engaging social network (S. Cacioppo et al., 2015; Hawkley, Browne, \& 
Cacioppo, 2005). As individuals high in extraversion tend to select situations high in sociality (Sherman et al., 2015), individuals low in extraversion might experience more social loneliness because their everyday situations tend to be lower in sociality.

In addition to these three moderators, we had initially pre-registered to test the reciprocity of the relation between personality and loneliness. However, we could not test this in the present meta-analysis because the overall number of longitudinal studies measuring both constructs at more than one time point was not sufficient to draw sound conclusions.

\section{Testing the Robustness of Effects Using Meta-Analysis}

While there is a stronger theoretical rationale for some moderator tests (as described above), other variables were included in the form of robustness checks. These robustness checks tested whether the relation between a certain personality trait and loneliness can be robustly found across different types of studies and samples. Mathematically, the approach does not differ between the moderator analyses and the robustness checks (i.e., both are meta-regressions). We use the term moderator analysis for meta-regressions with strong theoretical rationales. We use the term robustness checks for all other meta-regressions.

Taken together, in this study, we examined the following two sample characteristics: Average age and percentage of men. Moreover, we examined three study characteristics: publication year, publishing status (published vs. unpublished), and study type (cross-sectional vs. repeated-measured study). Last, we investigated the following four measurement characteristics: loneliness scale used (DJG-LS, UCLA, other), loneliness dimension (overall loneliness, social loneliness, emotional loneliness, other), underlying personality framework (Five Factor Model, Three Factor Model, other), and the reliability of the loneliness and the personality measures. Examples of loneliness scales coded as “other" were, for example, the 
SELSA (DiTommaso \& Spinner, 1993) or single item measures. Examples of personality frameworks coded as "other" were, for example, the HEXACO (Lee \& Ashton, 2004) or the PF16 (Cattell, Eber, \& Tatsuoka, 1970). We initially aimed to also examine the proportion of ethnic minority participants in the sample as a moderator. Moreover, although we had preregistered to exclude clinical samples, we decided during the coding process to rather include them and test the health status of the sample as a moderator. However, due to a lack of studies reporting the ethnic minority status and health status of the sample, we were not able to test these effects.

\section{Overview and Aims of the Present Study}

The main aim of this meta-analysis was to synthesize results from a large number of published and unpublished studies investigating relations between loneliness and personality. We also examined potential moderators of these relations (e.g., age of the sample, loneliness dimension). The present meta-analysis is the first large-scale systematic review of studies including personality and loneliness measures. This meta-analysis does not only provide a more accurate estimate of the bivariate relations between the Big Five traits and loneliness than single studies, it also estimates how much unique variance in loneliness each personality trait explains when controlling for the other four personality traits.

\section{Method}

\section{Literature Search and Inclusion Criteria}

Eligible studies were identified in two steps (Figure 1). In Step 1a, we conducted a standardized literature search in PsycINFO in November 2017 applying the search string ((isolation or loneliness or lonely) AND (personality OR "big five" OR "big 5" OR "five-factor model" OR OCEAN OR FFM OR openness OR conscientiousness OR extraversion OR 
introversion OR agreeableness OR neuroticism OR "emotional stability") in title and abstract. This search was restricted to empirical studies with a human sample published in English or German. No restriction was set regarding publication type or health status of the sample. This resulted in 506 studies. In Step 1b, we added studies from the MASLO-project. The MASLOproject is a large database aimed to include all studies that used one of the eight main standardized loneliness questionnaires (also see http://www.marliesmaes.com/maslo-project/). For that project, a literature search had been conducted using the databases PsycINFO, ERIC, PubMed, and Web of Science with the names of the loneliness measures as search terms. Finally, in Step 1c, we screened the full texts to determine whether an article could be included. In the rare case that no full text was available, we screened the abstract. No re-analyses of existing findings or statistical duplicates (e.g., data used in both a thesis and a journal article) were included. In cases where multiple publications were based on the same data, only one publication was included and priority was given to publications reporting (a) larger sample sizes, (b) more measurement points, and/or (c) more descriptive statistics.

In Step 2, we searched for and coded relevant data in the publications. In Step 2a, we checked whether the articles from Step 1 provided zero-order correlation coefficients for the relation between loneliness and personality. If no zero-order correlations were reported, the corresponding authors were invited via email to provide this information. Out of 578 articles, 487 had to be excluded because they failed to meet the inclusion criteria (see Figure 1 for details). This process thus resulted in 91 eligible studies. Finally, in Step $2 b$ we used the Society for Personality and Social Psychology (SPSP) forum Connect! as well as the email distribution list of the German Psychological Society (DGPs) to solicit unpublished data including 
personality and loneliness. This request resulted in 22 additional unpublished data sets. A total number of 113 studies were included in our meta-analyses.

\section{Coding of Studies}

A standardized coding manual and coding sheet were developed and tested before coding to ensure sufficient standardization of our coding process. Definitions of all coding categories

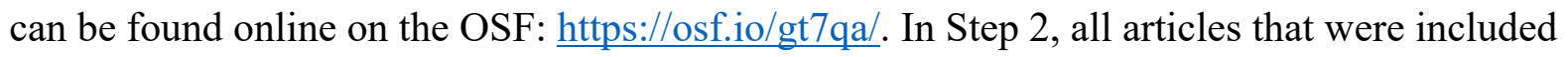
after Step 1 screening were coded for effect sizes and study characteristics by the first author. An experienced graduate student double-coded half of the studies in Step 1 and again half of the studies in Step 2. Overall, the average percentage of interrater agreement was $95 \%$ (for more details, see the online supplementary material (OSM)). In the rare cases of disagreement between the coders, the original article was consulted together.

To allow addressing the research question whether the relation between one personality trait and loneliness changes when controlling for the other four personality traits, we used metaanalytic structural equation modelling (MASEM; see below for a description of this approach). MASEM analyzes a meta-analytic covariance matrix. We therefore also coded the intercorrelations among the personality traits for all articles that were included in Step 2. The percentage of interrater agreement between both coders was $100 \%$ for these effect sizes.

In cases in which necessary information for the inclusion of a single study was missing in the paper (i.e., missing correlations on the relevant outcomes), the authors were contacted via email. In total, we contacted 69 authors of which $48 \%$ responded with the requested information. An overview of all descriptive characteristics that were coded for each included article can be found online at https://osf.io/gt7qa/. This table includes effect sizes and both study and sample characteristics for each included study. 


\section{Final Database for the Meta-Analyses}

The final database comprised 1,697 effect sizes from 113 studies with 136 independent samples and overall 93,668 individuals. Of the effect sizes, 909 described the association between loneliness and personality (141 for openness; 142 for conscientiousness, 234 for extraversion; 165 for agreeableness; 227 for neuroticism). The other effect sizes described associations among the personality traits (788 effect sizes).

\section{Meta-Analytic Procedure}

The meta-analyses were conducted based on Fisher's $Z$ values to obtain unbiased estimates of the correlation coefficients (Shadish \& Haddock, 2009). To enhance interpretability and to allow comparison with other meta-analyses based on correlations, these $Z$-scores were subsequently back-transformed to $r$ for reporting in this manuscript. To synthesize all effect sizes of the bivariate relations between loneliness and personality, the robu function available in the $\mathrm{R}$ package robumeta (Fisher, Tipton, \& Zhipeng, 2017) was used. Publication bias was assessed with the R package metafor (Viechtbauer, 2017) and R package robumeta (Fisher et al., 2017). The MASEM was conducted with the R package metaSEM (Cheung, 2018). This analysis differs from the analyses we preregistered on the OSF. MASEM is superior compared to the initially planned SEM based on a series of univariate meta-analyses (Cheung, 2015; Jak \& Cheung, 2018).

\section{Estimation of Bivariate Effect Sizes}

Overall, 15 meta-analyses on bivariate relations were conducted ( 5 for the relations between loneliness and the Big Five personality traits, 10 for the intercorrelations among the Big Five personality traits). For all bivariate meta-analyses, we estimated random effects models because they allow for the generalization of the findings above and beyond the included study set 
(Hedges \& Vevea, 1998; Viechtbauer, 2010). As the majority of included studies reported several relevant effect sizes (e.g., multiple sub-facets of loneliness), these effect sizes were not statistically independent of each other (cf. Hedges, Tipton, \& Johnson, 2010). Classical fixed effects or random effects meta-analyses rely on the assumption that all included effect sizes are independent. Therefore, we used robust variance estimation (RVE) for the bivariate metaanalyses regarding personality and loneliness. RVE adjusts the standard errors of the effect sizes to account for dependency (Tanner-Smith \& Tipton, 2014; Tanner-Smith, Tipton, \& Polanin, 2016). However, if the number of studies included in a meta-analysis is small or moderate, test statistics and confidence intervals based on RVE may suffer from inflated Type I error (Tipton \& Pustejovsky, 2015). Therefore, we used small-sample correction in all our meta-analyses conducted using RVE, which leads to the limitation that RVE results should only be trusted if the degrees of freedom are larger than 4 (Tanner-Smith \& Tipton, 2014; Tipton, 2015). The magnitude of heterogeneity between study-average effects was assessed with $\tau^{2}$ (Deeks, Higgins, $\&$ Altman, 2008). Additionally, $I^{2}$ was used to indicate the proportion of variance due to variability in true effects rather than sampling error (Borenstein, Higgins, Hedges, \& Rothstein, 2017; Fisher et al., 2017; Higgins \& Thompson, 2002). In other words, an $I^{2}$ close to $100 \%$ shows that most of the observed variation in effect sizes would remain if we were somehow able to eliminate the sampling error (Borenstein et al., 2017).

\section{Estimation of Moderating Effects}

The analyses were conducted separately for each moderator. First, the average association between a personality trait and loneliness was estimated in each sub-group based on the coded study and sample characteristics (e.g., in the subset of cross-sectional studies). This procedure yielded separate estimates of the average effect size and indicators of heterogeneity for each sub- 
group. Second, to test for potential significant differences between effect sizes that were obtained in different sub-groups (e.g., cross sectional studies vs. repeated-measured studies), we performed mixed effects RVE meta-regressions. All continuous predictor variables were meancentered to enhance interpretability of the regression coefficients. For all categorically coded characteristics, we added dummy-coded predictor variables into the meta-regressions separately for each personality dimension (for details, see Tanner-Smith \& Tipton, 2014). We chose the moderator category that showed the descriptively strongest association with loneliness as reference category for all moderator analyses (see Tables 4-8). As the total number of included studies varied across moderator analyses, not all predictors mentioned above could be tested in each meta-analysis (e.g., personality framework).

\section{Estimation of Potential Publication Bias Issues}

The validity of any meta-analysis can be threatened by publication bias, a phenomenon in which studies with statistically significant results (often with larger effect sizes compared to nonsignificant results) are more likely to be published than null findings (Polanin, Tanner-Smith, \& Hennessy, 2016). To assess whether the present meta-analyses were affected by publication bias, the publication status (published in a peer-reviewed journal vs. unpublished data) was investigated as a potential moderator. Following recent recommendations for assessing and adjusting for publication bias (Carter, Schönbrodt, Gervais, \& Hilgard, 2019), we performed multiple tests to detect and adjust for publication bias including contour-enhanced funnel plots (Peters, Sutton, Jones, Abrams, \& Rushton, 2008), Egger's regression tests (Egger, Smith, Schneider, \& Minder, 1997), trim-and-fill analyses (Duval \& Tweedie, 2000), Precision Effect Test (PET), and the Precision Effect Estimate with Standard Errors (PEESE) (Stanley \& 
Doucouliagos, 2014). A detailed discussion of the publication bias tests used in this metaanalysis is provided in the OSM.

\section{Estimation of Multivariate Effects}

We assessed the unique relations of each Big Five personality trait with loneliness when controlling for the other four traits by adopting a two-stage structural equation modeling approach (TSSEM) to MASEM (Cheung, 2015; Cheung \& Chan, 2005b). MASEM combines meta-analytical techniques and structural equation modeling (SEM) to synthesize correlation matrices and fitting SEMs on the basis of a pooled correlation matrix (Cheung \& Chan, 2005a, 2005b; Cheung \& Cheung, 2016). An advantage of correlation-based MASEM is that it is able to handle missing correlation coefficients in the correlation matrix (e.g., if a study reports the correlations between extraversion and loneliness and between neuroticism and loneliness but not for the other personality traits) by relying on maximum likelihood estimation (Cheung \& Cheung, 2016; Jak \& Cheung, 2018). At Stage 1 of TSSEM, a pooled correlation matrix is estimated by synthesizing the correlation matrices from all included samples. For TSSEM analyses, we included only samples using a univariate measure of loneliness (i.e., the UCLA or the DJG-LS reporting overall loneliness) to reduce systematic heterogeneity among samples. Using multivariate methods, TSSEM accounts for the covariance between the included correlations and weighs each cell by its respective sample size. At Stage 2 of TSSEM, structural models are fitted based on the obtained pooled correlation matrix (for more details on the twostep approach, see Cheung \& Chan, 2005b). Whenever multiple effect sizes described the same relation within one sample (e.g., when multiple longitudinal associations on loneliness and extraversion were included), we averaged these effect sizes within the sample for the MASEM 
analysis. All R scripts including effect size calculating formulas and the raw data set used for our analyses can be found online at https://osf.io/gt7qa/.

\section{Results}

\section{Study Characteristics}

Across all meta-analyses, the sample sizes in the included single studies ranged from 30 to 11,211 participants with a median of 178 . The mean age ranged from 12 to 100 years $(M=$ $26.91, S D=14.99)$. The mean proportion of men ranged from $0 \%$ to $100 \%(M=40.14, S D=$ 21.74). Concurrent associations were described by 600 effect sizes; lagged associations (loneliness and personality were measured at least one day apart from each other) were described by 309 effect sizes. The median time interval between two repeated measurements was two years (ranging from 1 day to 17 years). About $70 \%$ of the included effect sizes stemmed from articles published in peer-reviewed journals and about 30\% were retrieved from dissertations or unpublished datasets. The year of publication (or year of data collection for unpublished datasets) of all included studies ranged from 1980 to $2018(M d=2014)$. The samples of the included studies came from 26 different countries (about 35\% from German samples and 25\% from US samples).

\section{Bivariate Relations Between the Big Five Personality Traits and Loneliness}

Meta-analytic estimates of the bivariate relations between loneliness and the Big Five personality traits can be found in Table 1. We report both effect sizes corrected for measurement unreliability $\left(r^{+}\right.$; Hunter $\&$ Schmidt, 2004) and effect sizes without this correction $(r) . I^{2}$ for the uncorrected effect sizes ranged from $87.63 \%$ to $98.36 \%$, indicating substantial variance due to variability in true effects rather than sampling error. 
It has been argued that the conventions for effect size interpretation proposed by Cohen (1992) are not appropriate for individual differences research (Funder \& Ozer, 2019; Gignac \& Szodorai, 2016). As preregistered, we therefore interpreted the magnitude of the effect sizes based on the guidelines by Gignac and Szodorai (2016), with $r=.10, r=.20$, and $r=.30$ corresponding to small, medium, and large effects, respectively. Using this standard, the relations between loneliness and extraversion $(r=-.370,95 \%$ CI [-.410, -.329]) and between loneliness and neuroticism $(r=.358,95 \%$ CI $[.321, .394])$ were large in magnitude. The relations between agreeableness and loneliness ( $r=-.243,95 \%$ CI [-.274, -.210]) and between conscientiousness and loneliness $(r=-.202,95 \%[-.232,-.171])$ were medium in magnitude. Openness $(r=-.107$, 95\% CI [-.134, -.081]) was weakly related to loneliness. These results are consistent with our preregistered hypotheses.

\section{Assessing Publication Bias}

We took special care to retrieve as many unpublished studies as possible. Additionally, against the background of concerns regarding publication bias, we conducted extensive publication bias analyses. Contour-enhanced funnel plots with aggregated effect sizes at the study level (Peters et al., 2008) including trim-and-fill imputed studies can be found in Figure 2. Visual inspection indicated that most imputed effect sizes fell into the categories of nonsignificant results, suggesting a publication bias issue. Egger's tests for funnel plot asymmetry was not significant for the relation between loneliness and openness $(z=0.687, p=.492)$ and for the relation between loneliness and agreeableness $(z=-1.163, p=.245)$, providing little evidence for a publication bias issue. However, Egger's test was significant for the other personality traits, indicating a publication bias issue (Table 2). We additionally predicted the Fisher's $Z$ transformed effect size by its standard errors (PET) using the RVE technique. The slope was 
significant for extraversion $(b=-1.743,95 \%$ CI $[-3.133,-0.353])$, conscientiousness $(b=-1.256$, 95\% CI [-2.135, -0.377]), and neuroticism $(b=1.689,95 \%$ CI $[0.473,2.905])$, indicating publication bias. Results from Egger's regression based on aggregated effect sizes at the study level and Egger's regression using the RVE technique therefore corresponded to each other. Finally, publication status (published in a journal with peer-review process vs. unpublished) was tested as a predictor in all meta-analyses. This predictor was significant for the relation between loneliness and agreeableness only, indicating that effect sizes from published studies were significantly higher than effect sizes from unpublished data sets (see Table 5).

The main aim of the publication bias analyses was to evaluate whether the impact of this bias is negligible (Option A), whether the impact is not negligible but the major finding is still valid (Option B), or whether the major findings should be called into question (Option C) (cf. Borenstein, Hedges, Higgins, \& Rothstein, 2009). To address the extent to which publication bias may have influenced our analyses, we examined the adjusted effect size estimates according to Stanley and Doucouliagos (2014) PET-PEESE procedure using RVE the technique. Here, the PEESE-intercept can be interpreted as the most valid estimate of the effect size, adjusted for publication bias (Table 2). Adjusted effect sizes using PET-PEESE and original (unadjusted) effect sizes differed only slightly (as indicated by a comparison of correlation coefficient in Table 1 with PEESE-intercept $\beta_{0}$ in Table 2). This strengthens the conclusion that although publication bias was detected, our overall findings were only minimally affected by it.

\section{Multivariate Relations Between the Big Five Personality Traits and Loneliness}

The bivariate and the multivariate relations between the Big Five personality traits and loneliness from the MASEM approach are displayed in Table 3 (for meta-analytic intercorrelations among the Big Five personality traits, see Table S1 in the OSM). Estimates of 
the bivariate relations from the MASEM approach were comparable in magnitude to the estimates from the RVE approach presented in Table 1. As expected, all relations between a focal personality trait and loneliness decreased when controlling for the other four personality traits. The relation between openness and loneliness was no longer significantly different from zero when controlling for the other four personality traits. Conscientiousness was only weakly related to loneliness in the multivariate analyses. However, in the multivariate analyses, the negative relation between extraversion and loneliness remained medium to large in magnitude. In addition, a weak negative association between agreeableness and loneliness remained. Neuroticism was positively related to loneliness. This relation was slightly smaller in magnitude compared to the relation between extraversion and loneliness.

\section{Moderation Analyses and Robustness Checks in the Bivariate Models}

Here, we summarize the results of our moderation analyses and robustness checks. Full results can be found in Tables 4-8 (for a detailed description of the results, see the OSM). As summarized in Table 9, average age significantly moderated the relation between extraversion and loneliness as well as the relation between openness and loneliness. In line with our hypothesis, the negative relation between extraversion and loneliness became weaker (i.e., less negative) with increasing age $(b=.002,95 \%$ CI $[.000, .004])$. Note, however, that although this moderator was significant on a $95 \%$ confidence level in accordance with our hypothesis, the $p$ value was close to .05 (see Table 4). Therefore, this effect needs to be interpreted with caution and replication of this finding is necessary. The negative relation between openness and loneliness became stronger (i.e., more negative) with increasing age ( $b=-.002,95 \% \mathrm{CI}[-.003$, -.000]). The year of publication significantly moderated the relation between extraversion and loneliness as well as between neuroticism and loneliness. These relations became slightly weaker 
with increasing year of publication (for extraversion: $b=.005,95 \%$ CI $[.001, .009]$; for neuroticism: $b=-.005,95 \%$ CI [-.009, -.001]). Loneliness dimension significantly moderated the relations between loneliness and extraversion as well as between loneliness and neuroticism. The relation between extraversion and loneliness was weaker for emotional loneliness $\left(r^{+}=-.232\right.$, $95 \%$ CI $[-.344,-.114])$ than for the reference category of overall loneliness $\left(r^{+}=-.431,95 \% \mathrm{CI}\right.$ $[-.478,-.380])$. When switching the reference category to social loneliness, emotional loneliness was also weaker related to extraversion than social loneliness $\left(r^{+}=-.398,95 \%\right.$ CI $\left.[-.528,-.250]\right)$. The relation between neuroticism and loneliness was stronger for measures assessing overall loneliness (reference category; $r^{+}=.421,95 \%$ CI $[.376, .465]$ ) than for measures assessing social loneliness $\left(r^{+}=.287,95 \%\right.$ CI $\left.[.186, .381]\right)$ or for other measures that could not be definitely assigned as "overall”, "social loneliness" or "emotional loneliness" and were therefore coded as “other" $\left(r^{+}=.268,95 \%\right.$ CI $\left.[.173, .358]\right)$. When switching the reference category to emotional loneliness, neither social loneliness, overall loneliness, nor other loneliness dimensions differed significantly from this reference category. Moreover, the loneliness scale used significantly moderated all relations between loneliness and personality except for openness. Studies using the UCLA Loneliness Scale revealed the strongest association with personality traits compared to the DJG-LS, to other loneliness scales, or to both. This finding was also replicated by estimating the MASEM as described above in different sub-groups (i.e., the sub-group of studies using the UCLA scale as unidimensional measure vs. the sub-group of studies using the DJG-LS as unidimensional measure). Sub-group analysis is appropriate to determine how the structural models differ across levels of a categorical study-level variable (Jak \& Cheung, 2018). Coefficients differed in strengths from our overall random-effects models, yet the rank-order and direction of the associations stayed the same. Loneliness measured with the UCLA Loneliness 
Scale showed again higher correlations with personality than loneliness measured with the DJGLS. An overview of these MASEM sub-group results can be found in Table S2 and Table S3. Study type significantly moderated the relation between loneliness and neuroticism, indicating that the relation was stronger in cross-sectional studies $\left(r^{+}=.399,95 \% \mathrm{CI}\right.$ $[.357, .439])$ than in repeated-measured studies $\left(r^{+}=.316,95 \%\right.$ CI $\left.[.269, .360]\right)$. For all other relations between loneliness and personality traits, this moderator was not significant. Please note, however, that for repeated-measured studies the time interval between two measurements ranged from 1 day to 17 years. This heterogeneity might explain why this moderator was not significant in the majority of analyses. Publication status significantly moderated only the relation between loneliness and agreeableness, indicating that the relation was stronger in studies published in a peer-reviewed journal $\left(r^{+}=-.309,95 \%\right.$ CI $\left.[-.355,-.261]\right)$ than for unpublished studies $\left(r^{+}=-.226,95 \%\right.$ CI $\left.[-.279,-.171]\right)$. Regarding the other covariates included as robustness checks (percentage of males, underlying personality framework, reliability of personality and loneliness measure), we did not find any significant moderation effect, suggesting robustness of our results across these different sample and study characteristics.

\section{Discussion}

This meta-analysis aggregated studies including measures of personality traits and loneliness that were conducted over the last 38 years. Consistent with our preregistered hypotheses, extraversion, agreeableness, conscientiousness, and openness were negatively related to loneliness, and neuroticism was positively related to loneliness. By applying MASEM, we were able to estimate the unique relations of each Big Five trait with loneliness controlling for the overlap among the Big Five. For openness, the (small) association with loneliness did not remain statistically significant when controlling for the other personality traits. Thus, the relation 
between openness and loneliness was fully explained by the other four Big Five traits in the multivariate model or by general response tendencies. For all other traits, the unique predictive association with loneliness remained statistically significant, although they did decrease in magnitude compared to the bivariate associations. Thus, in contrast to previous single studies (e.g., Abdellaoui et al., 2018), neuroticism was not the only personality trait that was significantly related to loneliness when controlling for the other four personality traits in this meta-analysis. Extraversion and neuroticism showed the strongest relation with loneliness. In sum, we found that the average lonely person is rather introverted and neurotic, and somewhat less agreeable and conscientious than the average non-lonely person. However, it should be noted that lonely people can be very different from each other and these differences are likely to be larger than the differences between lonely and non-lonely people.

There are ongoing discussions if and to what extent loneliness should be conceptualized as a trait-like characteristic with similar features (i.e., similar heritability, stability, and change across the lifespan) as broader personality traits (Mund et al., 2019). However, when constructs are recognized as new personality traits, their relations to already existing personality traits should be clear to avoid redundancies and prevent so-called jingle-jangle fallacies (i.e., different labels used for the same construct). In the present meta-analysis, we show how loneliness can be embedded in a broader personality framework such as the FFM and thus enable a description of lonely individuals using the FFM as a lexical "coordinate system". Our meta-analytical results suggest that although broader personality traits and loneliness are interrelated, none of these relations is strong enough to speak of redundancy. However, to make statements as to whether a characteristic builds a core trait, other defining criteria (e.g., heritability) that were not examined in the current study need to be considered as well. 


\section{Robustness Checks and Moderating Effects}

Overall, our analyses of sub-groups of studies showed that the relation between personality traits and loneliness was relatively stable across various study and sample characteristics. However, some moderator effects differed among the relations between loneliness and the different personality traits (see Table 9 for a concise summary).

The finding that the bivariate negative association between extraversion and loneliness decreased with age was in line with our preregistered hypothesis. We expected the relationship between extraversion and loneliness to be stronger for adolescents than for (older) adults. Having an extraverted personality that is characterized by behaviors such as approaching strangers at a party thus seems to be more important for not getting lonely at a younger age. Consistent with this interpretation, a daily-life study by Wrzus, Wagner, and Riediger (2016) showed that the positive association between extraversion and the frequency of being with friends was moderated by age, such that young extraverted participants interacted more often with friends than older extraverted participants. In contrast, the bivariate negative relation between openness and loneliness increased with age. This age-differential association between openness and loneliness is in line with findings from research on the frequency of being with friends (Wrzus et al., 2016). Wrzus and colleagues (2016) showed that higher scores in openness in older adults were positively related to spending time with friends, potentially resulting in lower levels of loneliness. Trait openness appears to share similar neurophysiology with cognitive ability (DeYoung, Peterson, \& Higgins, 2005). Generally, cognitive ability in old age is a predictor of health (Deary, Whiteman, \& Starr, 2004). Healthy individuals in turn are better able to maintain their social relationships and tend to feel less lonely (Luo, Hawkley, Waite, \& Cacioppo, 2012). Although this may be a plausible explanation for the finding that openness and loneliness are 
more strongly (negatively) associated in older samples, it should be noted that the effect found here is small.

In further exploratory analyses, we tested whether the loneliness scale moderated the relation between the personality traits and loneliness. The loneliness scale was a significant moderator of all relations between personality traits and loneliness except openness. In most cases, the association between loneliness and personality was strongest when loneliness was measured using the UCLA Loneliness Scale. However, the relations were statistically significant independently of which loneliness scale was used (except for the analysis of the relation between conscientiousness and loneliness measured with the DJG-LS). It remains an open question why the strength of the relation between personality traits and loneliness differed as a function of how loneliness was measured. Note that we controlled for differences in the reliability of the scales by adjusting the effect sizes using Spearman's correction for attenuation (Hunter \& Schmidt, 2004).

Based on these findings, we believe that the field of loneliness research would greatly benefit from a debate if different loneliness scales such as the UCLA Loneliness Scale and the DJG-LS capture identical constructs. For example, there might be differences in the bandwidth (narrow vs. broad) of the loneliness construct captured with the UCLA Loneliness Scale compared to the DJG-LS, leading to differences in the magnitude of associations with broader personality traits. Usually scores of scales with a broader item content (such as the UCLA Loneliness Scale) produce higher correlations with other broader constructs such as personality traits than scales with a more focused and narrower item content (such as the DJG-LS). Furthermore, the UCLA Loneliness Scale and the DJG-LS differ not only in content and number of items, but also in the response format used. Whereas the UCLA Loneliness Scale is used with a four to five point Likert scale ranging from "never" to "always" (Russell, Peplau, \& Cutrona, 
1980), the DJG-LS is used with a three point scale with the response categories "yes", "more or less" and "no" (De Jong Gierveld \& van Tilburg, 2010). As the response format of the UCLA Loneliness scale is more similar to the response format of commonly used personality scales, there might be higher correlations between scores of these scales due to a more similar response behavior of participants on these scales. This is also reflected in corresponding differences in the multivariate analyses. Additionally, the DJG-LS comes with the disadvantage that all positively formulated (i.e., reverse-coded) items refer to social loneliness and all negatively formulated items refer to emotional loneliness (De Jong Gierveld \& van Tilburg, 2006), resulting in a confounding of item content and valence. This might explain differences between personalityloneliness-relations in dependence of which scale was used to measure loneliness.

We found that extraversion was more strongly related to social loneliness than to emotional loneliness. Social loneliness is described as the perceived absence of an engaging social network and is associated with the number of friends, whereas emotional loneliness is characterized by the perceived absence of close attachments (S. Cacioppo et al., 2015; Weiss, 1973). Extraverts enjoy being around people, so trying to be embedded in a larger social network seems to be extraversion-related behavior. Therefore, it might come as no surprise that the negative relation between extraversion is stronger for social loneliness (i.e., feeling insufficiently embedded in a larger social network) than for emotional loneliness. For the relation with neuroticism, we found less strong relations with social loneliness compared to overall loneliness. However, we did not find a significant difference in the relation between neuroticism and social loneliness compared to neuroticism and emotional loneliness. These results suggest that neuroticism is positively related to all aspects of loneliness. This is consistent with findings that 
indicate that neuroticism is both related to one's own negative behavior and greater perceived negativity through perceptual construal in social interactions (McNulty, 2008).

The relations between extraversion and loneliness as well as between neuroticism and loneliness were moderated by the year of the publication such that the mean association between personality and loneliness was stronger in older studies than in more recently published studies. One explanation could be that longitudinal studies, which produced slightly weaker effects in the present meta-analysis, have become more prevalent. However, the effects of publication year were small and should be interpreted with caution.

\section{Future Directions, Recommendations, and Caveats}

This meta-analysis on the relationship between loneliness and personality leads to several recommendations for future research directions. First, the present meta-analysis focused on concurrent relations as only few longitudinal studies were available. In most longitudinal studies, personality was measured at the first time point only and loneliness was measured at subsequent time points. It was therefore not possible to examine the direction of this association or to examine potential bidirectional associations between personality and loneliness. Personality might be related to loneliness because personality traits by definition capture typical behaviors, thoughts, and feelings (McCrae \& Costa, 2008). These behaviors (e.g., attending social events or not), thoughts (e.g., negatively biased perception of other people), and feelings (e.g., being anxious) are likely to have an impact on how we see others, how we are seen by others, how we interact with them, and how we interpret and cope with social interaction outcomes. This, in turn, may impact our social relationships and, consequently, our experience of loneliness. However, loneliness could also have effects on personality. Mund and Neyer (2016) examined the bidirectional longitudinal associations between personality and loneliness. They found that 
loneliness was predictive of both future levels of and changes in conscientiousness, extraversion, and neuroticism. Moreover, in another study, loneliness was found to predict personality five years later (Mund \& Neyer, 2018). In an experience sampling study, Hawkley, Burleson, Berntson, and Cacioppo (2003) found that loneliness predicted later cognitive appraisals of everyday events that can be described as neurotic tendencies. In sum, whereas this meta-analysis describes the nature and magnitude of the relations between loneliness and personality, both directions of the effects are plausible. To draw sound conclusions on the direction of the effect of personality and loneliness, more longitudinal studies that measure both constructs at multiple measurement points and experimental studies are needed.

Second, this meta-analysis examined the relation between loneliness and personality on the broad level of personality domains. However, loneliness and personality can also be related on other levels of personality (e.g., considering facets of personality; DeYoung et al., 2007). Future meta-analyses on the relation between loneliness and personality facets may yield a more fine-grained portrayal of how personality and loneliness are interwoven.

Third, all included studies reported correlations between self-reports because no studies measuring personality or loneliness with other methods such as informant reports or behavioral data were available. In future research, researchers might examine the relation between loneliness and peer-reported personality traits, or objective behavior related to personality traits. Such a multimethod approach would allow disentangling the true relation of personality and loneliness from those associations that are only due to common method variance. Although loneliness is commonly defined as an internal perception of missing quality and quantity of social relationships, self- and informant reports of loneliness are correlated (Luhmann, Bohn, 
Holtmann, Koch, \& Eid, 2016). We therefore hope that future studies will increasingly make use of informant reports of loneliness.

Fourth, as loneliness is defined as the perceived discrepancy between one's desired and one's actual social relationships, our results do not tell whether this discrepancy emerged because personality is more strongly associated with the desired social relationships or with the actual social relationships. In the case of extraversion, it is not very plausible that this trait's negative relation to loneliness would result from less desired relationships because this trait is predictive of the enjoyment of social interactions (Lucas \& Diener, 2001). However, it is an open question whether neurotic people's higher loneliness is due to a more intense (preoccupied) desire for intimacy, a tendency to regard relationships as threatened, or both.

Fifth, this meta-analysis presents a rigorous test of the relations between the Big Five and loneliness. Other constructs that are related to loneliness such as depression or anxiety show similar although not identical relations with the Big Five (for a meta-analysis see Kotov, Gamez, Schmidt, \& Watson, 2010). Neuroticism was positively and conscientiousness was negatively related to psychopathology (Kotov et al., 2010). However, agreeableness and openness were unrelated to the analyzed diagnoses (Kotov et al., 2010), which differs from our results for loneliness. This again strengthens the assumption that loneliness, depression, and anxiety are related but distinct constructs.

Note that we had originally planned to test whether the associations between personality traits and loneliness are robust across sample characteristics such as health status or ethnic minority status. However, only very few studies in our database investigated ethnic minorities, and most studies were conducted in western countries like Germany and the USA. Moreover, despite the attention to loneliness in the clinical context, almost no study explicitly reported data 
on personality and loneliness in clinical samples. We were therefore not able to test these moderators. We recommend studying the relationship between personality and loneliness in clinical and ethnic minority samples.

\section{Conclusion}

This meta-analysis provides a rigorous test of the interrelations between loneliness and personality traits. We examined the bivariate relations between loneliness and personality traits as well as the unique associations of each personality trait with loneliness over and above the other four traits in the FFM. In both bivariate and multivariate models, the strongest associations were found for extraversion (negative association) and neuroticism (positive association). To a lesser extent, agreeableness and conscientiousness were negatively related to loneliness. Openness did not seem to play a predominant role in the context of loneliness. We also found, however, that these associations between loneliness and personality differed in strength depending on how loneliness is assessed. Understanding how personality and loneliness are related is not only of interest from a theoretical perspective, but can also have practical implications, for example by informing prevention and intervention strategies against loneliness. Specifically, the knowledge of the associations between personality and loneliness can point out personality-typical behaviors related to loneliness such as introverted and emotionally unstable states that could be considered in therapeutic settings. Future research applying a personality psychological perspective on loneliness will also help to identify who is at risk to develop loneliness and help to understand when and why some people experience loneliness and others do not. 


\section{References}

References marked with an asterisk $(*)$ indicate studies included in the meta-analyses.

Abdellaoui, A., Chen, H.-Y., Willemsen, G., Ehli, E. A., Davies, G. E., Verweij, K. J. H., ... Cacioppo, J. T. (2019). Associations between loneliness and personality are mostly driven by a genetic association with neuroticism. Journal of Personality, 87(2), 386-397. https://doi.org/10.1111/jopy.12397

*Abu-Raiya, H., Pargament, K. I., Krause, N., \& Ironson, G. (2015). Psychological distress, and well-being in a national sample of American adults. American Journal of Orthopsychiatry, 85(6), 565-575. https://doi.org/10.1037/ort0000084

*Alcorta, A., Ancer, J., Saldívar, D., Guzmán, S., Bermúdez, M. V., Montes, J., ... Zambrano, S. M. F. (2008). Measurement of psychosocial health in medical students: Validation of the Jefferson Medical College's Questionnaire in Mexico. Interdisciplinaria, 25(1), 101-119.

*Amichai-Hamburger, Y., \& Ben-Artzi, E. (2003). Loneliness and internet use. Computers in Human Behavior, 19(1), 71-80. https://doi.org/10.1016/S0747-5632(02)00014-6

*Ammirati, R. J. (2013). Self-assessed emotion recognition skill and social adjustment among college students (Doctoral dissertation). Emory University, Atlanta, USA.

*Anam-ul-Malik, \& Rafiq, N. (2016). Exploring the relationship of personality, loneliness, and online social support with interned addiction and procrastination. Pakistan Journal of Psychological Research, 31(1), 93-117. https://doi.org/10.1037/0033-2909.133.1.65

Anderson, C., John, O. P., Keltner, D., \& Kring, A. M. (2001). Who attains social status? Effects of personality and physical attractiveness in social groups. Journal of Personality and Social Psychology, 81(1), 116-132. https://doi.org/10.1037//0022-3514.81.1.116 
*Ano, G. G., \& Pargament, K. I. (2013). Predictors of spiritual struggles: An exploratory study. Mental Health, Religion and Culture, 16(4), 419-434. https://doi.org/10.1080/13674676.2012.680434

*Asendorpf, J. B., \& Van Aken, M. A. G. (2003). Personality - Relationship transaction in adolescence: Core versus surface personality characteristics. Journal of Personality, 71(4), 629-666. https://doi.org/10.1111/1467-6494.7104005

Asendorpf, J. B., \& Wilpers, S. (1998). Personality effects on social relationships. Journal of Personality and Social Psychology, 74(6), 1531-1544. https://doi.org/10.1037/0022$\underline{3514.74 .6 .1531}$

*Barke, A., Nyenhuis, N. \& Kröner-Herwig, B. (2014). [The relation between loneliness and the Big Five personality in a large online survey]. Unpublished raw data.

Barrick, M. R., Mount, M. K., \& Li, N. (2013). The theory of purposeful work behavior: The role of personality, job characteristics, and experienced meaningfulness. Academy of Management Review, 38(1), 1-51. https://doi.org/10.5465/amr.2010.0479

Baumeister, R. F., \& Leary, M. R. (1995). The need to belong: Desire for interpersonal attachments as a fundamental human motivation. Psychological Bulletin, 117(3), 497529. https://doi.org/10.1037/0033-2909.117.3.497

*Beadle, J. N., Keady, B., Brown, V., Tranel, D., \& Paradiso, S. (2012). Trait empathy as a predictor of individual differences in perceived loneliness. Psychological Reports, 110(1), 3-15. https://doi.org/10.2466/07.09.20.PR0.110.1.3-15

*Becker, M. (2008). Personality and social network variables as predictors of adjustment: The transition from high school to college (Doctoral dissertation). Boston University, Boston, USA. 
*Bishop, A. J., \& Martin, P. (2007). The indirect influence of educational attainment on loneliness among unmarried older adults. Educational Gerontology, 33(10), 897-917. https://doi.org/10.1080/03601270701569275

Borenstein, M., Hedges, L. V., Higgins, J. P. T., \& Rothstein, H. R. (2009). Introduction to metaanalysis. Chichester, UK: Wiley. https://doi.org/10.1002/9780470743386

Borenstein, M., Higgins, J. P. T., Hedges, L. V., \& Rothstein, H. R. (2017). Basics of metaanalysis: I2 is not an absolute measure of heterogeneity. Research Synthesis Methods, 8(1), 5-18. https://doi.org/10.1002/jrsm.1230

*Boujut, E., \& Bruchon-Schweitzer, M. (2009). A construction and validation of a freshman stress questionnaire: An exploratory study. Psychological Reports, 104(2), 680-692. https://doi.org/10.2466/pr0.104.2.680-692

Breil, S. M., Geukes, K., Wilson, R. E., Nestler, S., Vazire, S., \& Back, M. D. (2019). Zooming into real-life extraversion - how personality and situation shape sociability in social interactions. Collabra: Psychology, 5(1), 1-28. https://doi.org/10.1525/collabra.170

*Buchanan, T., \& Whitty, M. T. (2014). The online dating romance scam: causes and consequences of victimhood. Psychology, Crime and Law, 20(3), 261-283. https://doi.org/10.1080/1068316X.2013.772180

*Bulut Serin, N. (2011). An examination of predictor variables for problematic internet use. Turkish Online Journal of Educational Technology, 10(3), 54-62.

*Büssing, A., Baumann, K., Jacobs, C., \& Frick, E. (2017). Spiritual dryness in Catholic priests: Internal resources as possible buffers. Psychology of Religion and Spirituality, 9(1), 4655. https://doi.org/10.1037/rel0000063 
*Butkovic, A., Brkovic, I., \& Bratko, D. (2012). Predicting well-being from personality in adolescents and older adults. Journal of Happiness Studies, 13(3), 455-467. https://doi.org/10.1007/s10902-011-9273-7

Cacioppo, J. T., \& Patrick, B. (2008). Loneliness: Human nature and the need for social connection. New York, NY: Norton.

*Cacioppo, J. T., Hawkley, L. C., \& Thisted, R. A. (2010). Perceived social isolation makes me sad: Five year cross-lagged analyses of loneliness and depressive symptomatology in the Chicago Health, Aging, and Social Relations Study. Psychology and Aging, 25(2), 453463. https://doi.org/10.1037/a0017216.

Cacioppo, S., Grippo, A. J., London, S., Goossens, L., \& Cacioppo, J. T. (2015). Loneliness: Clinical import and interventions. Perspectives on Psychological Science, 10(2), 238249. https://doi.org/10.1177/1745691615570616

Carter, E. C., Schönbrodt, F. D., Gervais, W. M., \& Hilgard, J. (2019). Correcting for bias in psychology: A comparison of meta-analytic methods. Advances in Methods and Practices in Psychological Science, 2(2), 115-144. https://doi.org/10.1177/2515245919847196

*Casini, E., Preti, E., \& Richetin, J. (2017). [The relation between loneliness and personality in an ecological momentary assessment study on an Italian sample of adolescents]. Unpublished raw data.

Cattell, R. B., Eber, H. W., \& Tatsuoka, M. M. (1970). Handbook for the Sixteen Personality Factor Questionnaire. Champaign, IL: Institute for Personality and Ability Testing. *CentERdata (Tilburg University, The Netherlands). (2018). [The relation between loneliness and personality in the LISS (Longitudinal Internet Studies for the Social sciences) panel]. Unpublished raw data. 
*Chapman, B. P. (2007). Bandwidth and fidelity on the NEO-Five Factor Inventory:

Replicability and reliability of Saucier's (1998) item cluster subcomponents. Journal of Personality Assessment, 88(2), 220-234. https://doi.org/10.1080/00223890701268082

*Chapman, B. P., \& Hayslip, B. (2010). Incremental validity of a measure of emotional intelligence incremental validity of a measure of emotional intelligence. Journal of Personality Assessment, 85(2), 154-169. https://doi.org/10.1207/s15327752jpa8502_08

Cheng, H., \& Furnham, A. (2002). Personality, peer relations, and self-confidence as predictors of happiness and loneliness. Journal of Adolescence, 25, 327-339. https://doi.org/10.1006/yjado.475

Cheung, M. W.-L. (2015). Meta-analysis: A structural equation modeling approach. Chichester, UK: Wiley.

Cheung, M. W.-L. (2018). Package “metaSEM.” Retrieved from https://cran.rproject.org/web/packages/metaSEM/metaSEM.pdf

Cheung, M. W.-L., \& Chan, W. (2005a). Classifying correlation matrices into relatively homogeneous subgroups: A cluster analytic approach. Educational and Psychological Measurement, 65(6), 954-979. https://doi.org/10.1177/0013164404273946

Cheung, M. W.-L., \& Chan, W. (2005b). Meta-analytic structural equation modeling: A two-stage approach. Psychological Methods, 10(1), 40-64. https://doi.org/10.1037/1082$\underline{989 X .10 .1 .40}$

Cheung, M. W.-L., \& Cheung, S. F. (2016). Random-effects models for meta-analytic structural equation modeling: review, issues, and illustrations. Research Synthesis Methods, 7(2), 140-155. https://doi.org/10.1002/jrsm.1166 
Cohen, J. (1992). A power primer. Psychological Bulletin, 120(1), 155-159. https://doi.org/10.1038/141613a0

Costa, P. T., \& McCrae, R. R. (1980). Influence of extraversion and neuroticism on subjective well-being: Happy and unhappy people. Journal of Personality and Social Psychology, 38(4), 668-678. https://doi.org/10.1037/0022-3514.38.4.668

*Crisp, D. A., Windsor, T. D., Butterworth, P., \& Anstey, K. J. (2015). Adapting to retirement community life: Changes in social networks and perceived loneliness. Journal of Relationships Research, 6(e9), 1-12. https://doi.org/10.1017/jrr.2015.5

*De Cock, R., Vangeel, J., Klein, A., Minotte, P., Rosas, O., \& Meerkerk, G.-J. (2014).

Compulsive use of social networking sites in Belgium: Prevalence, profile, and the role of attitude toward work and school. Cyberpsychology, Behavior, and Social Networking, 17(3), 166-171. https://doi.org/10.1089/cyber.2013.0029

De Jong Gierveld, J., \& Van Tilburg, T. (2006). A 6-item scale for overall, emotional, and social loneliness - Confirmatory tests on survey data. Research on Aging, 28(5), 582-598. https://doi.org/10.1177/0164027506289723

De Jong Gierveld, J., \& van Tilburg, T. (2010). The De Jong Gierveld short scales for emotional and social loneliness: Tested on data from 7 countries in the UN generations and gender surveys. European Journal of Ageing, 7(2), 121-130. https://doi.org/10.1007/s10433$\underline{010-0144-6}$

Deary, I. J., Whiteman, M. C., \& Starr, J. M. (2004). The impact of childhood intelligence in later life: Following up the Scottish Mental Surveys of 1932 and 1947. Journal of Personality and Social Psychology, 86, 130-147. https://doi.org/10.1037/0022-3514.86.1.130 
*Deatherage, S. S. (2017). Facebook engagement on college students' interpersonal and intrapersonal functioning (doctoral dissertation). Retrieved from ProQuest Dissertations and Theses database. UMI 3402307. https://doi.org/UMI 3402307

Deeks, J. J., Higgins, J. P. T., \& Altman, D. G. (2008). Analysing data and undertaking metaanalyses. In J. P. T. Higgins \& S. Green (Eds.), Cochrane handbook for systematic reviews of interventions: Cochrane Book Series (pp. 243-296). Chichester, UK: Wiley.

Denissen, J. J. A., \& Penke, L. (2008). Neuroticism predicts reactions to cues of social inclusion. European Journal of Personality, 22, 497-517. https://doi.org/10.1002/per.682

DeYoung, C. G., Peterson, J. B., \& Higgins, D. M. (2005). Sources of openness/intellect: Cognitive and neuropsychological correlates of the fifth factor of personality. Journal of Personality, 73, 825-858. https://doi.org/10.1111/J.1467-6494.2005.00330.X

DeYoung, C. G., Quilty, L. C., \& Peterson, J. B. (2007). Between facets and domains: 10 aspects of the Big Five. Journal of Personality and Social Psychology, 93(5), 880-896. https://doi.org/10.1037/0022-3514.93.5.880

*Diewald, M., Riemann, R., Spinath, F. M., Gottschling, J., Hahn, E., Kornadt, A. E., ... Peters, A.-L. (2018). [TwinLife]. Cologne: GESIS Data Archive. https://doi.org/doi:10.4232/1.13072

DiTommaso, E., \& Spinner, B. (1993). The development and initial validation of the social and emotional loneliness scale (SELSA). Personality and Individual Differences, 14(1), 127134. https://doi.org/10.1016/0191-8869(93)90182-3

DiTommaso, E., \& Spinner, B. (1997). Social and emotional loneliness: An examination of Weiss's typology of loneliness. Personality and Individual Differences, 22(3), 417-427. https://doi.org/10.1037/0022-3514.46.6.1313 
Dufner, M., Arslan, R. C., Hagemeyer, B., Schönbrodt, F. D., \& Denissen, J. J. A. (2015).

Affective contingencies in the affiliative domain: Physiological assessment, associations with the affiliation motive, and prediction of behavior. Journal of Personality and Social Psychology, 109(4), 662-676. https://doi.org/10.1037/pspp0000025

Duval, S., \& Tweedie, R. (2000). Trim and fill: A simple funnel-plot-based method of testing and adjusting for publication bias in meta-analysis. Biometrics, 56, 455-463. https://doi.org/10.1111/j.0006-341X.2000.00455.X

Eaton, L. G., \& Funder, D. C. (2003). The creation and consequences of the social world: An international analysis of extraversion. European Journal of Personality, 17, 375-395. https://doi.org/10.1002/per.477

Egger, M., Smith, G. D., Schneider, M., \& Minder, C. (1997). Bias in meta-analysis detected by a simple, graphical test. BMJ Clinical Research, 315, 629-634. https://doi.org/10.1136/bmj.316.7129.469

*Eisses, A. M. H., Kluiter, H., Jongenelis, K., Pot, A. M., Beekman, A. T. F., \& Ormel, J. (2004). Risk indicators of depression in residential homes. International Journal of Geriatric Psychiatry, 19(7), 634-640. https://doi.org/10.1002/gps.1137

*Engelberg, E., \& Sjöberg, L. (2004). Emotional intelligence, affect intensity, and social adjustment. Personality and Individual Differences, 37(3), 533-542. https://doi.org/10.1016/j.paid.2003.09.024

*Engelberg, E., \& Sjöberg, L. (2004). Internet use, social skills, and adjustment. CyberPsychology \& Behavior, 7(1), 41-47. https://doi.org/10.1089/109493104322820101 
*Engelberg, E., \& Sjöberg, L. (2007). Money obsession, social adjustment, and economic risk perception. Journal of Socio-Economics, 36(5), 686-697. https://doi.org/10.1016/j.socec.2007.01.005

*Fees, B. S., Martin, P., \& Poon, L. W. (1999). A model of loneliness in older adults. The Journals of Gerontology Series B: Psychological Sciences and Social Sciences, 54B(4), 231-239. https://doi.org/10.1093/geronb/54B.4.P231

Fisher, Z., Tipton, E., \& Zhipeng, H. (2017). robumeta: Robust variance meta-regression. R package version 2.0. Retrieved from https://cran.r-project.org/package=robumeta

Fleeson, W., \& Gallagher, P. (2009). The implications of Big Five standing for the distribution of trait manifestation in behavior: Fifteen experience-sampling studies and a meta-analysis. Journal of Personality and Social Psychology, 97(6), 1097-1114. https://doi.org/10.1037/a0016786

*Floyd, L. J. (2002). Loneliness: Personality correlates and psychophysiological consequences (Doctoral dissertation). Howard University, Washington, D.C., USA.

*Freund, A. M., \& Baltes, P. B. (1999). Selection, optimization, and compensation as strategies of life management: Correction to Freund and Bates (1998). Psychology and Aging, 14(4), 700-702. https://doi.org/10.1037//0882-7974.14.4.700

Funder, D. C., \& Ozer, D. J. (2019). Evaluating effect size in psychological research: Sense and nonsense. Advances in Methods and Practices in Psychological Science, 2(2), 156-168. https://doi.org/10.1177/2515245919847202

Gignac, G. E., \& Szodorai, E. T. (2016). Effect size guidelines for individual differences researchers. Personality and Individual Differences, 102, 74-78. https://doi.org/10.1016/j.paid.2016.06.069 
*Gouin, J. P., Zhou, B., \& Fitzpatrick, S. (2015). Social integration prospectively predicts changes in heart rate variability among individuals undergoing migration stress. Annals of Behavioral Medicine, 49(2), 230-238. https://doi.org/10.1007/s12160-014-9650-7

Grygiel, P., Humenny, G., Rebisz, S., Świtaj, P., \& Sikorska, J. (2013). Validating the Polish adaptation of the 11-item De Jong Gierveld Loneliness Scale. European Journal of Psychological Assessment, 29, 129-139. https://doi.org/10.1027/1015-5759/a000130

*Günay, E. (2012). The effects of internet use on individual's socialization based on personality traits. New/Yeni Symposium Journal, 50, 123-133.

*Hagemeyer, B., Neyer, F. J., Neberich, W., \& Asendorpf, J. B. (2013). The ABC of Social Desires: Affiliation, being alone, and closeness to partner. European Journal of Personality, 27(5), 442-457. https://doi.org/10.1002/per.1857

*Halamandaris, K. F., \& Power, K. G. (1997). Individual differences, dysfunctional attitudes, and social support: A study of the psychosocial adjustment to university life of home students. Personality and Individual Differences, 22(1), 93-104. https://doi.org/10.1016/S0191$\underline{8869(96) 00175-4}$

*Halamandaris, K. F., \& Power, K. G. (1999). Individual differences, social support and coping with the examination stress: A study of the psychosocial and academic adjustment of first year home students. Personality and Individual Differences, 26(4), 665-685. https://doi.org/10.1016/S0191-8869(98)00172-X

Hawkley, L. C., \& Cacioppo, J. T. (2010). Loneliness matters: A theoretical and empirical review of consequences and mechanisms. Annals of Behavioral Medicine, 40(2), 218-227. https://doi.org/10.1007/s12160-010-9210-8 
Hawkley, L. C., Browne, M. W., \& Cacioppo, J. T. (2005). How can I connect with thee? Let me count the ways. Psychological Science, 16(10), 798-804. https://doi.org/10.1111/j.1467$\underline{9280.2005 .01617 . x}$

*Hawkley, L. C., Burleson, M. H., Berntson, G. G., \& Cacioppo, J. T. (2003). Loneliness in everyday life: Cardiovascular activity, psychosocial context, and health behaviors. Journal of Personality and Social Psychology, 85(1), 105-120. https://doi.org/10.1037/0022-3514.85.1.105

Hedges, L. V., \& Vevea, J. L. (1998). Fixed- and random-effects models in meta-analysis. Psychological Methods, 3(4), 486-504. https://doi.org/10.1037/1082-989X.3.4.486

Hedges, L. V., Tipton, E., \& Johnson, M. C. (2010). Robust variance estimation in metaregression with dependent effect size estimates. Research Synthesis Methods, 1(1), 39-65. https://doi.org/10.1002/jrsm.5

*Hensley, B., Martin, P., Margrett, J. A., MacDonald, M., Siegler, I. C., \& Poon, L. W. (2012). Life events and personality predicting loneliness among centenarians: Findings from the Georgia centenarian study. Journal of Psychology: Interdisciplinary and Applied, 146(12), 173-188. https://doi.org/10.1080/00223980.2011.613874

Higgins, J. P. T., \& Thompson, S. G. (2002). Quantifying heterogeneity in a meta-analysis. Statistics in Medicine, 21(11), 1539-1558. https://doi.org/10.1002/sim.1186

*Hojat, M. (1982). Psychometric characteristics of the UCLA Loneliness Scale: A study with Iranian college students. Educational and Psychological Measurement, 42, 917-925. https://doi.org/10.1177/001316448204200328

*Hojat, M., \& Lyons, K. (1998). Psychosocial characteristics of female students in the allied health and medical colleges: Psychometrics of the measures and personality profiles. 
Advances in Health Sciences Education, 3(2), 119-132.

https://doi.org/10.1023/A:1009733623166

Horstmann, K. T., Rauthmann, J. F., Sherman, R. A., \& Ziegler, M. (2019). Unveiling an exclusive link: Predicting behavior with personality, situation perception, and affect in a pre-registered experience sampling study. Unpublished Manuscript.

Hunter, J. E., \& Schmidt, F. L. (2004). Methods of meta-analysis: Correcting error and bias in research findings (2nd ed.). Thousand Oaks, CA: Sage.

Jak, S., \& Cheung, M. W. L. (2018). Testing moderator hypotheses in meta-analytic structural equation modeling using subgroup analysis. Behavior Research Methods, 50(4), 13591373. https://doi.org/10.3758/s13428-018-1046-3

Jensen-Campbell, L. A., Adams, R., Perry, D. G., Workman, K. A., Furdella, J. Q., \& Egan, S. K. (2002). Agreeableness, extraversion, and peer relations in early adolescence: Winning friends and deflecting aggression. Journal of Research in Personality, 36(3), 224-251. https://doi.org/10.1006/jrpe.2002.2348

John, O. P., Robins, R. W., \& Pervin, L. A. (2008). Handbook of personality: Theory and research (3rd ed.). New York, NY: Guilford Press. https://doi.org/10.1016/B978$\underline{012134645-4 / 50022-6}$

*Kamath, M., \& Kanekar, S. (1993). Loneliness, shyness, self-esteem, and extraversion. Journal of Social Psychology, 133(6), 855-857. https://doi.org/10.1080/00224545.1993.9713949

*Klose, D. (2015). Are frequency and duration of social interactions correlated with subcomponents of social intelligence? An ambulatory assessment (Master's thesis). Ottovon-Guericke University Magdeburg, Magdeburg, Germany. 
*Kokkinos, C. M., \& Saripanidis, I. (2017). A lifestyle exposure perspective of victimization through Facebook among university students. Do individual differences matter? Computers in Human Behavior, 74, 235-245. https://doi.org/10.1016/j.chb.2017.04.036

*Kong, X., Wei, D., Li, W., Cun, L., Xue, S., Zhang, Q., \& Qiu, J. (2014). Neuroticism and extraversion mediate the association between loneliness and the dorsolateral prefrontal cortex. Experimental Brain Research, 233(1), 157-164. https://doi.org/10.1007/s00221$\underline{014-4097-4}$

*Korn, M. E., \& Maggs, J. L. (2004). Why drink less? Diffidence, self-presentation styles, and alcohol use among university students. Journal of Youth and Adolescence, 33(3), 201211. https://doi.org/10.1023/B:JOYO.0000025319.57979.13

Kotov, R., Gamez, W., Schmidt, F., \& Watson, D. (2010). Linking “Big” personality traits to anxiety, depressive, and substance use disorders: A meta-analysis. Psychological Bulletin, 136(5), 768-821. https://doi.org/10.1037/a0020327

*Krasko, J., Intelisano, S., \& Luhmann, M. (2018). [The happiness week study]. Unpublished raw data.

*Krasko, J., Intelisano, S., \& Luhmann, M. (2018). Novel measures of conceptualizations of happiness: Lay definitions, complexity of definitions, and intentions to pursue happiness. Unpublished Manuscript.

*Kritzler, S. (2018). [The relation between loneliness and personality in a German ESM study]. Unpublished raw data.

*LaRose, R., \& Tsai, H. S. (2014). Computers in human behavior completion rates and nonresponse error in online surveys: Comparing sweepstakes and pre-paid cash incentives in 
studies of online behavior. Computers in Human Behavior, 34, 110-119.

https://doi.org/10.1016/j.chb.2014.01.017

*Lasgaard, M. (2007). Reliability and validity of the Danish version of the UCLA Loneliness

Scale. Personality and Individual Differences, 42(7), 1359-1366.

https://doi.org/10.1016/j.paid.2006.10.013

*Leck, K. (2006). Correlates of minimal dating. Journal of Social Psychology, 146(5), 549-567. https://doi.org/10.3200/SOCP.146.5.549-567

Lee, K., \& Ashton, M. C. (2004). Psychometric properties of the HEXACO personality inventory. Multivariate Behavioral Research, 39(2), 329-358. https://doi.org/10.1207/s15327906mbr3902

*Lee, S., Tam, C. L., \& Chie, Q. T. (2014). Mobile phone usage preferences: The contributing factors of personality, social anxiety and loneliness. Social Indicators Research, 118(3), 1205-1228. https://doi.org/10.1007/s11205-013-0460-2

Lehmann, R., Denissen, J. J. A., Allemand, M., \& Penke, L. (2013). Age and gender differences in motivational manifestations of the Big Five from age 16 to 60. Developmental Psychology, 49(2), 365-383. https://doi.org/10.1037/a0028277

*Letzring, T. D. (2015). Observer judgmental accuracy of personality: Benefits related to being a good (normative) judge. Journal of Research in Personality, 54, 51-60. https://doi.org/10.1016/j.jrp.2014.05.001

*Levin, I., \& Stokes, J. P. (1986). An examination of the relation of individual difference variables to loneliness. Journal of Personality, 54(4), 717-733. https://doi.org/10.1111/j.1467-6494.1986.tb00422.x 
*Lindner, C., Dannlowski, U., Walhöfer, K., Rödiger, M., Maisch, B., Bauer, J., ... Suslow, T. (2014). Social alienation in schizophrenia patients: Association with insula responsiveness to facial expressions of disgust. PLoS ONE, 9(1). https://doi.org/10.1371/journal.pone.0085014

*Liu, H., Wang, Y., Liu, W., Wei, D., Yang, J., Du, X., ... Qiu, J. (2016). Neuroanatomical correlates of attitudes toward suicide in a large healthy sample: A voxel-based morphometric analysis. Neuropsychologia, 80, 185-193. https://doi.org/10.1016/j.neuropsychologia.2015.11.012

*Long, C. R., Seburn, M., Averill, J. R., \& More, T. A. (2003). Solitude experiences: Varieties, settings, and individual differences. Personality and Social Psychology Bulletin, 29, 578583. https://doi.org/10.1177/0146167203251535

*Long, M. V., \& Martin, P. (2000). Personality, relationship closeness, and loneliness of oldest old adults and their children. Journals of Gerontology - Series B Psychological Sciences and Social Sciences, 55(5), 311-319. https://doi.org/10.1093/geronb/55.5.P311

*Lu, A., Yu, Y., Hong, X., Feng, Y., Tian, H., \& Liao, J. (2014). Peer attachment and loneliness among adolescents who are deaf: The moderating effect of personality. Social Behavior and Personality: An International Journal, 42(4), 551-560. https://doi.org/10.2224/sbp.2014.42.4.551

Lucas, R. E., \& Diener, E. (2001). Understanding extraverts' enjoyment of social situations: The importance of pleasantness. Journal of Personality and Social Psychology, 81(2), 343356. https://doi.org/10.1037/0022-3514.81.2.343 
Lucas, R. E., Le, K., \& Dyrenforth, P. S. (2008). Explaining the extraversion/positive affect relation: Sociability cannot account for extraverts' greater happiness. Journal of Personality, 76(3), 385-414. https://doi.org/10.1111/j.1467-6494.2008.00490.x

*Luhmann, M. (2011). [AWB vs CWB experiment]. Unpublished raw data.

*Luhmann, M. (2012). [Simoland study]. Unpublished raw data.

*Luhmann, M. (2013). [LS manipulation study at UIC]. Unpublished raw data.

*Luhmann, M., \& Kalitzki, A. (2016). [The relation between loneliness and personality in pet owners]. Unpublished raw data.

Luhmann, M., Bohn, J., Holtmann, J., Koch, T., \& Eid, M. (2016). I'm lonely, can't you tell? Convergent validity of self- and informant ratings of loneliness. Journal of Research in Personality, 61, 50-60. https://doi.org/10.1016/j.jrp.2016.02.002

Luo, Y., Hawkley, L. C., Waite, L. J., \& Cacioppo, J. T. (2012). Loneliness, health, and mortality in old age: A national longitudinal study. Social Science and Medicine, 74(6), 907-914. https://doi.org/10.1016/j.socscimed.2011.11.028

*Lutsky, N. (2018). [The relation between loneliness and personality in US students]. Unpublished raw data.

*Maes, M., Vanhalst, J., Spithoven, A. W. M., Van den Noortgate, W., \& Goossens, L. (2016). Loneliness and attitudes toward aloneness in adolescence: A person-centered approach. Journal of Youth and Adolescence, 45(3), 547-567. https://doi.org/10.1007/s10964-015$\underline{0354-5}$

Maes, M., Vanhalst, J., Van den Noortgate, W., \& Goossens, L. (2017). Intimate and relational loneliness in adolescence. Journal of Child and Family Studies, 26(8), 2059-2069. https://doi.org/10.1007/s10826-017-0722-8 
*Mancini, A. D., Sinan, B., \& Bonanno, G. A. (2015). Predictors of prolonged grief, resilience, and recovery among bereaved spouses. Journal of Clinical Psychology, 71(12), 12451258. https://doi.org/10.1002/jclp.22224

*Martin, J. I. (1995). Intimacy, loneliness, and openness to feelings in adult children of alcoholics. Health and Social Work, 20(1), 52-59. https://doi.org/10.1093/hsw/20.1.52

*McConnell, A. R., Brown, C. M., Shoda, T. M., Stayton, L. E., \& Martin, C. E. (2011). Friends with benefits: On the positive consequences of pet ownership. Journal of Personality and Social Psychology, 101(5), 1239-1252. https://doi.org/10.1037/a0024506

McCrae, R. R. (1996). Social consequences of experiential openness. Psychological Bulletin, 120(3), 323-337. https://doi.org/10.1037/0033-2909.120.3.323

McCrae, R. R., \& Costa, P. T. (2008). The five-factor theory of personality. In O. P. John, R. W. Robins, \& L. A. Pervin (Eds.), Handbook of personality: Theory and research (pp. 159181). New York, US: Guilford Press.

McNulty, J. K. (2008). Neuroticism and interpersonal negativity: The independent contributions of perceptions and behaviors. Personality and Social Psychology Bulletin, 34(11), 14391450. https://doi.org/10.1177/0146167208322558

Mervielde, I., \& De Fruyt, F. (2000). The big five personality factors as a model for the structure of children's peer nominations. European Journal of Personality, 14(2), 91-106. https://doi.org/10.1002/(SICI)1099-0984(200003/04)14:2<91::AID-PER356>3.0.CO;2-Z

*Mund, M., \& Neyer, F. J. (2016). The winding paths of the lonesome cowboy: Evidence for mutual influences between personality, subjective health, and loneliness. Journal of Personality, 84(5), 646-657. https://doi.org/10.1111/jopy.12188 
Mund, M., \& Neyer, F. J. (2018). Loneliness effects on personality. International Journal of Behavioral Development, 43(2), 136-146. https://doi.org/10.1177/0165025418800224

Mund, M., Freuding, M. M., Möbius, K., Horn, N., \& Neyer, F. J. (2019). The stability and change of loneliness across the life span: A meta-analysis of longitudinal studies. Personality and Social Psychology Review, 1-29. https://doi.org/10.1177/1088868319850738

*Naqshbandi, M. M., Ainin, S., Jaafar, N. I., \& Mohd Shuib, N. L. (2017). To Facebook or to Face Book? An investigation of how academic performance of different personalities is affected through the intervention of Facebook usage. Computers in Human Behavior, 75, 167-176. https://doi.org/10.1016/j.chb.2017.05.012

*Nayyar, S., \& Singh, B. (2011). Personality correlates of loneliness. Journal of the Indian Academy of Applied Psychology, 37(1), 163-168.

*Neubauer, A. B., \& Voss, A. (2016). Validation and revision of a German version of the balanced measure of psychological needs scale. Journal of Individual Differences, 37(1), 56-72. https://doi.org/10.1027/1614-0001/a000188

Nikitin, J., \& Freund, A. M. (2015). The indirect nature of social motives: The relation of social approach and avoidance motives with likeability via extraversion and agreeableness. Journal of Personality, 83(1), 97-105. https://doi.org/10.1111/jopy.12086

*Nozaki, Y., \& Koyasu, M. (2016). Can we apply an emotional competence measure to an Eastern population? Psychometric properties of the profile of emotional competence in a Japanese population. Assessment, 23(1), 112-123.

https://doi.org/10.1177/1073191115571124 
*Ohtsubo, Y., Masuda, T., Matsunaga, M., Noguchi, Y., Yamasue, H., \& Ishii, K. (2018). Is collectivistic forgiveness so much different from individualistic forgiveness? Dispositional correlates of trait forgivingness in Canada and Japan. Unpublished Manuscript.

*Oishi, S., Krochik, M., Roth, D., \& Sherman, G. D. (2012). Residential mobility, personality, and subjective and physical well-being: An analysis of cortisol secretion. Social Psychological and Personality Science, 3(2), 153-161. https://doi.org/10.1177/1948550611412395

*Olmstead, S. B., Roberson, P. N. E., \& Fincham, F. D. (2012). Early psychological distress is a precursor to college men's later academic and social adjustment. College Student Journal, $50,53-58$.

Peters, J. L., Sutton, A. J., Jones, D. R., Abrams, K. R., \& Rushton, L. (2008). Contour-enhanced meta-analysis funnel plots help distinguish publication bias from other causes of asymmetry. Journal of Clinical Epidemiology, 61(10), 991-996. https://doi.org/10.1016/j.jclinepi.2007.11.010

Polanin, J. R., Tanner-Smith, E. E., \& Hennessy, E. A. (2016). Estimating the difference between published and unpublished effect sizes: A meta-review. Review of Educational Research, 86(1), 207-236. https://doi.org/10.3102/0034654315582067

*Rassart, J., Luyckx, K., Goossens, E., Oris, L., Apers, S., \& Moons, P. (2016). A Big Five personality typology in adolescents with congenital heart disease: Prospective associations with psychosocial functioning and perceived health. International Journal of Behavioral Medicine, 23(3), 310-318. https://doi.org/10.1007/s12529-016-9547-x 
*Reardon, K. W., Wang, M., Neighbors, C. N., \& Tackett, J. L. (n.d.). Personality and gambling behaviors in adolescence: The importance of sensation seeking. Unpublished Manuscript.

*Reis, H. T. (2018). [The relation between loneliness and personality in newlywed couples]. Unpublished raw data.

*Riley, B. B. (1994). Multiple determinants of loneliness: The joint influence of situational and characterological factors (Doctoral dissertation). The University of Toledo, Toledo, USA.

Roberts, B. W., Wood, D., \& Caspi, A. (2008). The development of personality traits in adulthood. In O. P. John, R. W. Robins, \& L. A. Pervin (Eds.), Handbook of personality: Theory and research (3rd ed., pp. 375-398). New York, US: Guilford Press.

*Ropponen, A., Svedberg, P., Huunan-Seppälä, A., Koskenvuo, K., Koskenvuo, M., Alexanderson, K., ... Kaprio, J. (2012). Personality traits and life dissatisfaction as risk factors for disability pension due to low back diagnoses: A 30-year longitudinal cohort study of Finnish twins. Journal of Psychosomatic Research, 73(4), 289-294. https://doi.org/10.1016/j.jpsychores.2012.07.003

*Russell, D. W. (1996). UCLA Loneliness Scale version 3: Reliability, validity, and factor structure. Journal of Personality and Social Psychology, 66(1), 20-40. https://doi.org/10.1207/s15327752jpa6601

Russell, D. W., Cutrona, C. E., Rose, J., \& Yurko, K. (1984). Social and emotional loneliness: An examination of Weiss's typology of loneliness. Journal of Personality and Social Psychology, 46(6), 1313-1321. https://doi.org/10.1037/0022-3514.46.6.1313

*Russell, D. W., Peplau, L. A., \& Cutrona, C. E. (1980). The revised UCLA Loneliness Scale: Concurrent and discriminant validity evidence. Journal of Personality and Social Psychology, 39(3), 472-480. https://doi.org/10.1037//0022-3514.39.3.472 
*Sagioglou, C. (2018). [The relation between loneliness and the Big Five personality in students]. Unpublished raw data.

*Saklofske, D. H., \& Yackulic, R. A. (1989). Personality predictors of loneliness. Personality and Individual Differences, 10(4), 467-472. https://doi.org/10.1016/0191$\underline{8869(89) 90011-1}$

*Saklofske, D. H., Yackulic, R. A., \& Kelly, I. W. (1986). Personality and loneliness. Personality and Individual Differences, 7(6), 899-901. https://doi.org/10.1016/0191-8869(86)90091$\underline{7}$

*Sandstrom, G. M. (2018). [The relation between loneliness and personality in an interactions intervention study]. Unpublished raw data.

*Sandstrom, G. M., \& Dunn, E. W. (2014). Social interactions and well-being: The surprising power of weak ties. Personality and Social Psychology Bulletin, 40(7), 910-922. https://doi.org/10.1177/0146167214529799

*Sandstrom, G. M., Tseng, V. W. S., Costa, J., Okeke, F., Choudhury, T., \& Dunn, E. W. (2016). [The relation between loneliness and personality in a mobile sensing pilot study]. Unpublished raw data.

*Schindler, I. (2011). [Study on emotion and life style (SEULE)]. Unpublished raw data.

*Schnittger, R. I. B., Wherton, J., Prendergast, D., \& Lawlor, B. A. (2012). Risk factors and mediating pathways of loneliness and social support in community-dwelling older adults. Aging \& Mental Health, 16(3), 335-346. https://doi.org/10.1080/13607863.2011.629092

*Schutter, N., \& Comijs, H. C. (2018). [The relation between loneliness and the Big Five personality in The Netherlands study of depression in older persons (NESDO)]. Unpublished raw data. 
*Schwab, R., \& Petersen, K. U. (1990). Religiousness: Its relation to loneliness, neuroticism and subjective well-being. Journal for the Scientific Study of Religion, 29(3), 335-345. https://doi.org/10.2307/1386462

Selfhout, M., Burk, W., Branje, S., Denissen, J., van Aken, M., \& Meeus, W. (2010). Emerging late adolescent friendship networks and big five personality traits: A social network approach. Journal of Personality, 78(2), 509-538. https://doi.org/10.1111/j.1467$\underline{6494.2010 .00625 . x}$

Shadish, W. R., \& Haddock, C. K. (2009). Combining estimates of effect size. In H. Cooper, L. V. Hedges, \& J. C. Valentine (Eds.), The handbook of research synthesis and metaanalysis (pp. 257-277). New York, NY: Russell Sage Foundation.

*Shen, C., \& Williams, D. (2011). Unpacking time online: Connecting internet and massively multiplayer online game use with psychosocial well-being. Communication Research, 38(1), 123-149. https://doi.org/10.1177/0093650210377196

Sherman, R. A., Rauthmann, J. F., Brown, N. A., Serfass, D. G., \& Jones, A. B. (2015). The independent effects of personality and situations on real-time expressions of behavior and emotion. Journal of Personality and Social Psychology, 109(5), 872-888. https://doi.org/10.1037/pspp0000036

*Skues, J. L., Williams, B., \& Wise, L. (2012). The effects of personality traits, self-esteem, loneliness, and narcissism on Facebook use among university students. Computers in Human Behavior, 28(6), 2414-2419. https://doi.org/10.1016/j.chb.2012.07.012

Song, Y., \& Shi, M. (2017). Associations between empathy and big five personality traits among Chinese undergraduate medical students. PLoS ONE, 12(2), 1-13. https://doi.org/10.1371/journal.pone.0171665 
*Spielmann, S. S., MacDonald, G., Maxwell, J. A., Joel, S., Peragine, D., Muise, A., \& Impett, E. A. (2013). Settling for less out of fear of being single. Journal of Personality and Social Psychology, 105(6), 1049-1073. https://doi.org/10.1037/a0034628

Stanley, T. D., \& Doucouliagos, H. (2014). Meta-regression approximations to reduce publication selection bias. Research Synthesis Methods, 5(1), 60-78. https://doi.org/10.1002/jrsm.1095

*Stephan, E., Fäth, M., \& Lamm, H. (1988). Loneliness as related to various personality and environmental measures: research with the German adaptation of the UCLA Loneliness Scale. Social Behavior and Personality, 16(2), 169-174. https://doi.org/10.2224/sbp.1988.16.2.169

*Steptoe, A., \& Wardle, J. (2017). Life skills, wealth, health, and wellbeing in later life. Proceedings of the National Academy of Sciences, 114(17), 4354-4359. https://doi.org/10.1073/pnas.1616011114

*Stöber, J. (2003). Self-Pity: Exploring the links to personality, control beliefs, and anger. Journal of Personality, 71(2), 183-220. https://doi.org/10.1111/1467-6494.7102004

*Stokes, J. P. (1985). The relation of social network and individual differences in loneliness. Journal of Personality and Social Psychology, 48(4), 981-991. https://doi.org/10.1037/0022-3514.48.4.981

*Stroebe, M., Van Vliet, T., Hewstone, M., \& Willis, H. (2002). Homesickness among students in two cultures: Antecedents and consequences. British Journal of Psychology, 93(2), 147168. https://doi.org/10.1348/000712602162508

*Sunardi, Y. (2014). Predictive factors for commitment to the priestly vocation: A study of priests and seminarians (Doctoral dissertation). Marquette University, Milwaukee, USA. 
Tanner-Smith, E. E., \& Tipton, E. (2014). Robust variance estimation with dependent effect sizes: Practical considerations including a software tutorial in Stata and SPSS. Research Synthesis Methods, 5(1), 13-30. https://doi.org/10.1002/jrsm.1091

Tanner-Smith, E. E., Tipton, E., \& Polanin, J. R. (2016). Handling complex meta-analytic data structures using robust variance estimates: a tutorial in R. Journal of Developmental and Life-Course Criminology, 2(1), 85-112. https://doi.org/10.1007/s40865-016-0026-5

*Teppers, E., Klimstra, T. A., van Damme, C., Luyckx, K., Vanhalst, J., \& Goossens, L. (2013). Personality traits, loneliness, and attitudes toward aloneness in adolescence. Journal of Social and Personal Relationships, 30(8), 1045-1063. https://doi.org/10.1177/0265407513481445

Tipton, E. (2015). Small sample adjustments for robust variance estimation. Psychological Methods, 20(3), 375-393. https://doi.org/10.1037/met0000011

Tipton, E., \& Pustejovsky, J. E. (2015). Small-sample adjustments for tests of moderators and model fit using robust variance estimation in meta-regression. Journal of Educational and Behavioral Statistics, 40(6), 604-634. https://doi.org/10.3102/1076998615606099

Tobin, R. M., Graziano, W. G., Vanman, E. J., \& Tassinary, L. G. (2000). Personality, emotional experience, and efforts to control emotions. Journal of Personality and Social Psychology, 79(4), 656-669. https://doi.org/10.1037/0022-3514.79.4.656

*van der Aa, N., Overbeek, G., Engels, R. C. M. E., Scholte, R. H. J., Meerkerk, G. J., \& Van Den Eijnden, R. J. J. M. (2009). Daily and compulsive internet use and well-being in adolescence: A diathesis-stress model based on big five personality traits. Journal of Youth and Adolescence, 38(6), 765-776. https://doi.org/10.1007/s10964-008-9298-3 
van der Linden, D., Scholte, R. H. J., Cillessen, A. H. N., Nijenhuis, J. T., \& Segers, E. (2010). Classroom ratings of likeability and popularity are related to the Big Five and the general factor of personality. Journal of Research in Personality, 44(5), 669-672. https://doi.org/10.1016/j.jrp.2010.08.007

van Zalk, M., \& Denissen, J. J. A. (2015). Idiosyncratic versus social consensus approaches to personality: self-view, perceived, and peer-view similarity. Journal of Personality and Social Psychology, 109(1), 121-141. https://doi.org/10.1037/pspp0000035

*Vanhalst, J., Klimstra, T. A., Luyckx, K., Scholte, R. H. J., Engels, R. C. M. E., \& Goossens, L. (2012). The interplay of loneliness and depressive symptoms across adolescence: Exploring the role of personality traits. Journal of Youth and Adolescence, 41(6), 776787. https://doi.org/10.1007/s10964-011-9726-7

Vater, A., \& Schröder-Abé, M. (2015). Explaining the link between personality and relationship satisfaction: Emotion regulation and interpersonal behaviour in conflict discussions. European Journal of Personality, 29(2), 201-215. https://doi.org/10.1002/per.1993

Viechtbauer, W. (2010). Conducting meta-analyses in R with the metafor package. Journal of Statistical Software, 36(3), 1-48. https://doi.org/10.1103/PhysRevB.91.121108

Viechtbauer, W. (2017). Package "metafor". Retrieved from https://cran.rproject.org/web/packages/metafor/metafor.pdf

*Vrangalova, Z., \& Bukberg, R. E. (2015). Are sexually permissive individuals more victimized and socially isolated? Personal Relationships, 22(2), 230-242.

https://doi.org/10.1111/pere.12076 
*Wagner, J., Ram, N., Smith, J., \& Gerstorf, D. (2016). Personality trait development at the end of life: Antecedents and correlates of mean-level trajectories. Journal of Personality and Social Psychology, 111(3), 411-429. https://doi.org/10.1037/pspp0000071

*Wardenaar, K. J., Monden, R., Conradi, H. J., \& Jonge, P. De. (2015). Symptom-specific course trajectories and their determinants in primary care patients with Major Depressive Disorder: Evidence for two etiologically distinct prototypes. Journal of Affective Disorders, 179, 38-46. https://doi.org/10.1016/j.jad.2015.03.029

*Wästlund, E., Norlander, T., \& Archer, T. (2001). Internet blues revisited: Replication and extension of an internet paradox study. CyberPsychology \& Behavior, 4(3), 385-391. https://doi.org/10.1089/109493101300210295

Weiss, R. S. (1973). Loneliness: The experience of emotional and social isolation. Cambridge, MA: MIT Press.

*Wilson, D., Sibanda, J., Sibanda, P., \& Wilson, C. (1988). Personality concomitants of loneliness among black and white male Zimbabwean adolescents. Journal of Social Psychology, 129(4), 577-578. https://doi.org/10.1080/00224545.1989.9712079

*Woods, K. S. (2012). Loneliness, extraversion, and youth group involvement (Doctoral dissertation).

Wrzus, C., Wagner, G. G., \& Riediger, M. (2016). Personality-Situation transactions from adolescence to old age. Journal of Personality and Social Psychology, 110(5), 782-799. https://doi.org/10.1037/pspp0000054

Zautra, A. J., Affleck, G. G., Tennen, H. A., Reich, J. W., \& Davis, M. C. (2005). Dynamic approaches to emotions and stress in everyday life: Bolger and Zuckerman reloaded with 
positive as well as negative affects. Journal of Personality, 73(6), 1511-1538. https://doi.org/10.1111/j.0022-3506.2005.00357.x

*Ziemes, J. F. (2015). Identity development in gifted individuals (Master's thesis). Trier University, Trier, Germany. 
Table 1 Meta-Analytic Estimates of the Bivariate Relations Between Loneliness and Personality With and Without Correction for Measurement Error

\begin{tabular}{|c|c|c|c|c|c|c|c|c|c|c|c|}
\hline \multirow[b]{2}{*}{ Big Five trait } & \multirow[b]{2}{*}{$j$} & \multirow[b]{2}{*}{$k$} & \multirow[b]{2}{*}{$d f$} & \multicolumn{4}{|c|}{ Estimates corrected for measurement error } & \multicolumn{4}{|c|}{ Uncorrected estimates } \\
\hline & & & & $r^{+}$ & $95 \% \mathrm{CI}$ & $I^{2}$ & $\tau^{2}$ & $r$ & $95 \% \mathrm{CI}$ & $I^{2}$ & $\overline{\tau^{2}}$ \\
\hline Extraversion & 97 & 234 & 95.59 & -.403 & {$[-.447,-.357]$} & 98.38 & 0.094 & -.370 & {$[-.410,-.329]$} & 98.36 & 0.077 \\
\hline Agreeableness & 55 & 165 & 53.13 & -.268 & {$[-.304,-.231]$} & 96.81 & 0.043 & -.243 & {$[-.274,-.210]$} & 96.40 & 0.033 \\
\hline Conscientiousness & 56 & 142 & 50.99 & -.219 & {$[-.252,-.186]$} & 88.44 & 0.011 & -.202 & {$[-.232,-.171]$} & 87.63 & 0.009 \\
\hline Neuroticism & 99 & 227 & 97.47 & .394 & {$[.352, .434]$} & 97.89 & 0.076 & .358 & {$[.321, .394]$} & 97.76 & 0.058 \\
\hline Openness & 58 & 141 & 52.80 & -.118 & {$[-.147,-.089]$} & 89.24 & 0.012 & -.107 & {$[-.134,-.081]$} & 88.08 & 0.009 \\
\hline
\end{tabular}

Note. $j=$ number of studies, $k=$ number of effect sizes, $d f=$ degrees of freedom, $r^{+}=$meta-analytic correlation corrected for measurement error, $95 \%$ $\mathrm{CI}=95 \%$ confidence interval, $\tau^{2}=$ measure of heterogeneity, $I^{2}=$ proportion of variance due to variability in true effects rather than sampling error, $r=$ meta-analytic correlation without correction. 
Table 2 Egger's Regression Tests for Funnel Plot Asymmetry With Aggregated Effect Sizes at the Study Level and PET-PEESE Adjusted Effect Size Estimates

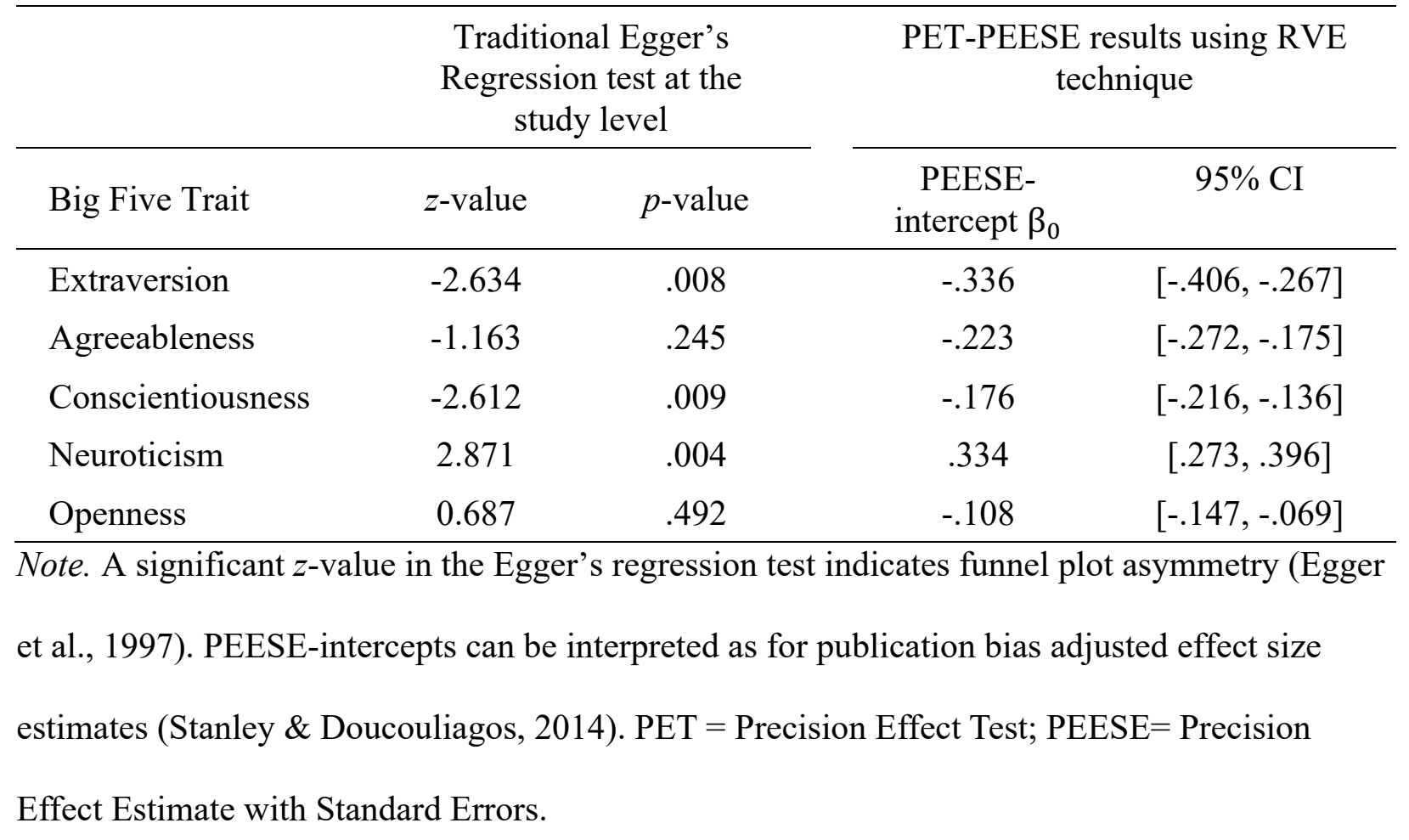


Table 3 Meta-Analytic Estimates of the Bivariate and Multivariate Relations Between Loneliness and Personality using MASEM

\section{Loneliness}

\begin{tabular}{lccccc}
\cline { 2 - 3 } \cline { 5 - 6 } Personality trait & \multicolumn{2}{c}{ Bivariate } & & \multicolumn{2}{c}{ Multivariate } \\
\cline { 2 - 3 } & ES & $95 \%$ CI & & ES & $95 \%$ CI \\
\hline Extraversion & -.397 & {$[-.438,-.356]$} & & -.304 & {$[-.353,-.255]$} \\
Agreeableness & -.260 & {$[-.293,-.228]$} & & -.128 & {$[-.169,-.086]$} \\
Conscientiousness & -.226 & {$[-.256,-.197]$} & & -.094 & {$[-.132,-.056]$} \\
Neuroticism & .382 & {$[.345, .419]$} & & .273 & {$[.227, .317]$} \\
Openness & -.120 & {$[-.150,-.089]$} & & .000 & {$[-.038, .039]$} \\
\hline
\end{tabular}

Note. MASEM = Meta-Analytic Structural Equation Modeling, ES = meta-analytic effect size; $95 \% \mathrm{CI}=95 \%$ confidence interval. Multivariate ES reflect the association between loneliness and the corresponding personality trait when controlling for all other personality traits. 
Table 4 Moderator Analyses for the Meta-Analyses on the Bivariate Relations of Loneliness and Extraversion

\begin{tabular}{|c|c|c|c|c|c|c|c|c|c|}
\hline Moderator level & $j$ & $k$ & $d f$ & $\mathrm{ES}$ & $95 \% \mathrm{CI}$ & $\tau^{2}$ & $I^{2}$ & $p$-value & $\begin{array}{l}\text { Reference } \\
\text { category }\end{array}$ \\
\hline Age & 74 & 152 & 9.64 & .002 & {$[.000, .004]$} & 0.098 & 98.38 & .046 & \\
\hline$\%$ men & 87 & 159 & 22.23 & -.001 & {$[-.003, .000]$} & 0.108 & 98.30 & .128 & \\
\hline Publication year & 91 & 202 & 20.81 & .005 & {$[.000, .009]$} & 0.087 & 98.25 & .023 & \\
\hline \multicolumn{10}{|l|}{ Publishing status } \\
\hline Published & 68 & 171 & 66.83 & -.421 & {$[-.476,-.363]$} & 0.137 & 98.64 & NA & REF \\
\hline Unpublished & 31 & 63 & 29.49 & -.371 & {$[-.432,-.305]$} & 0.035 & 96.10 & .208 & \\
\hline \multicolumn{10}{|l|}{ Study type } \\
\hline Repeated- & 14 & 74 & 12.36 & -.368 & {$[-.436,-.294]$} & 0.019 & 74.53 & .530 & \\
\hline \multicolumn{10}{|l|}{ measured study } \\
\hline Cross-sectional & 96 & 160 & 94.61 & -.408 & {$[-.452,-.362]$} & 0.094 & 98.40 & NA & REF \\
\hline \multicolumn{10}{|l|}{ Loneliness scale } \\
\hline DJG-LS & 7 & 16 & 5.99 & -.188 & {$[-.348,-.018]$} & 0.034 & 92.85 & .008 & \\
\hline Other & 20 & 40 & 18.76 & -.329 & {$[-.412,-.240]$} & 0.049 & 98.21 & .032 & \\
\hline UCLA & 74 & 177 & 72.57 & -.441 & {$[-.490,-.389]$} & 0.085 & 97.44 & NA & REF \\
\hline $\begin{array}{l}\text { Loneliness } \\
\text { dimension }\end{array}$ & & & & & & & & & \\
\hline $\begin{array}{l}\text { Overall } \\
\text { loneliness }\end{array}$ & 80 & 185 & 78.67 & -.431 & {$[-.478,-.380]$} & 0.107 & 98.58 & NA & REF \\
\hline Social & 13 & 16 & 11.93 & -.398 & {$[-.528,-.250]$} & 0.05 & 96.18 & .555 & \\
\hline
\end{tabular}


loneliness

$\begin{array}{llllllllll}\text { Emotional } & 14 & 19 & 12.88 & -.232 & {[-.344,-.114]} & 0.028 & 93.44 & .001\end{array}$

loneliness

Other

$\begin{array}{lllllll}7 & 13 & 5.95 & -.336 & {[-.415,-.252]} & 0.034 & 90.61\end{array}$

.088

Personality

framework

$\begin{array}{llllllllll}\text { Five Factor } & 64 & 182 & 62.55 & -.414 & {[-.465,-.361]} & 0.073 & 97.95 & .078\end{array}$

Model

Three Factor $\quad 26 \quad 41 \quad 24.95 \quad-.436 \quad[-.502,-.364] \quad 0.152 \quad 98.80 \quad$ NA $\quad$ REF

Model

$\begin{array}{llllllllll}\text { Other } & 8 & 11 & 7.00 & -.185 & {[-.464, .127]} & 0.234 & 98.67 & .641\end{array}$

$\begin{array}{lllllllllll}\text { Reliability of } & & 59 & 128 & 13.25 & -.694 & {[-.984, .601]} & 0.091 & 96.90 & .255\end{array}$

loneliness

measure

$\begin{array}{lllllllllll}\text { Reliability of } & & 54 & 112 & 17.15 & -.925 & {[-.998, .117]} & 0.117 & 98.21 & .066\end{array}$

personality

measure

Note. $j=$ number of studies, $k=$ number of effect sizes, $d f=$ degrees of freedom, ES = effect size (for categorical moderators, we report estimated mean correlation coefficients corrected for measurement error in the respective subset; for continuous moderators, we report regression coefficients out of the mixed effects RVE meta-regressions), 95\% CI $=95 \%$ confidence interval, $p$-values indicate whether one category differed from the reference category or whether a continuous moderator reached significance, $\mathrm{REF}=$ reference category. 
Table 5 Moderator Analyses for the Meta-Analyses on the Bivariate Relations of Loneliness and Agreeableness

\begin{tabular}{|c|c|c|c|c|c|c|c|c|c|}
\hline Moderator level & $j$ & $k$ & $d f$ & ES & $95 \% \mathrm{CI}$ & $\tau^{2}$ & $I^{2}$ & $p$-value & $\begin{array}{l}\text { Reference } \\
\text { category }\end{array}$ \\
\hline Age & 47 & 111 & 8.69 & .001 & {$[-.003, .004]$} & 0.044 & 96.08 & .678 & \\
\hline$\%$ men & 48 & 96 & 10.25 & -.003 & {$[-.005, .000]$} & 0.041 & 95.20 & .028 & \\
\hline Publication year & 49 & 135 & 9.96 & .013 & {$[-.002, .028]$} & 0.014 & 90.39 & .079 & \\
\hline \multicolumn{10}{|l|}{ Publishing status } \\
\hline Published & 30 & 112 & 28.48 & -.309 & {$[-.355,-.261]$} & 0.053 & 96.18 & NA & REF \\
\hline Unpublished & 27 & 53 & 24.83 & -.226 & {$[-.279,-.171]$} & 0.015 & 92.03 & .014 & \\
\hline
\end{tabular}

\section{Study type}

$\begin{array}{llllllllll}\text { Repeated- } & 12 & 69 & 10.27 & -.215 & {[-.296,-.131]} & 0.015 & 71.45 & .261\end{array}$

measured study

$\left.\begin{array}{lllllllll}\text { Cross-sectional } & 54 & 96 & 52.25 & -.269 & {[-.305,-.233}\end{array}\right] \quad 0.042 \quad 96.86 \quad$ NA $\quad$ REF

\section{Loneliness scale}

$\begin{array}{lllllllll}\text { DJG-LS } & 6 & 14 & 4.98 & -.157 & {[-.300,-.006]} & 0.021 & 87.74 & .046\end{array}$

$\begin{array}{llllllllll}\text { Other } & 11 & 21 & 8.79 & -.184 & {[-.236,-.130]} & 0.006 & 87.54 & .014\end{array}$

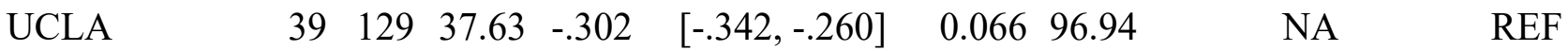

\section{Loneliness}

dimension

Overall

$\begin{array}{lllllll}42 & 131 & 40.49 & -.287 & {[-.328,-.246]} & 0.054 & 97.49\end{array}$

NA

REF

loneliness

Social

$9 \quad 12 \quad 7.26 \quad-.221 \quad[-.347,-.087] \quad 0.013 \quad 88.23$

.670 
loneliness

$\begin{array}{lllllllll}\text { Emotional } & 9 & 13 & 7.34 & -.147 & {[-.213,-.080]} & 0.004 & 72.79 & .002\end{array}$

loneliness

$\begin{array}{llllllllll}\text { Reliability of } & 28 & 78 & 2.95 & -.261 & {[-.889, .707]} & 0.047 & 93.61 & .510\end{array}$

loneliness

measure $^{\mathrm{a}}$

$\begin{array}{llllllllll}\text { Reliability of } & 27 & 66 & 7.32 & -.035 & {[-.629, .584]} & 0.045 & 94.27 & .910\end{array}$

personality

measure

Note. $j=$ number of studies, $k=$ number of effect sizes, $d f=$ degrees of freedom, ES $=$ effect size (for categorical moderators, we report estimated mean correlation coefficients corrected for measurement error in the respective subset; for continuous moderators, we report regression coefficients out of the mixed effects RVE meta-regressions), $95 \% \mathrm{CI}=95 \%$ confidence interval, $p$-values indicate whether one category differed from the reference category or whether a continuous moderator reached significance, $\mathrm{REF}=$ reference category.

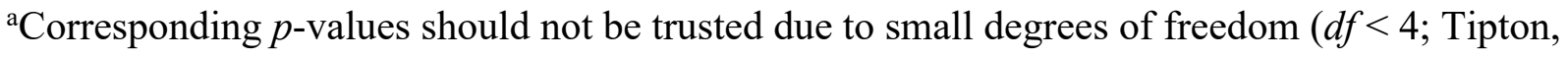
2015). 
Table 6 Moderator Analyses for the Meta-Analyses on the Bivariate Relations Between

Loneliness and Conscientiousness

\begin{tabular}{|c|c|c|c|c|c|c|c|c|c|}
\hline Moderator level & $j$ & $k$ & $d f$ & ES & $95 \% \mathrm{CI}$ & $\tau^{2}$ & $I^{2}$ & $p$-value & $\begin{array}{l}\text { Reference } \\
\text { category }\end{array}$ \\
\hline Age & 49 & 113 & 8.74 & -.002 & {$[.005, .001]$} & 0.014 & 8.57 & .117 & \\
\hline \% men & 50 & 98 & 10.70 & -.001 & {$[-.003, .001]$} & 0.015 & 7.79 & .285 & \\
\hline Publication year & 50 & 112 & 10.70 & .008 & {$[-.006, .021]$} & 0.013 & 9.36 & .230 & \\
\hline \multicolumn{10}{|l|}{ Publishing status } \\
\hline Published & 30 & 87 & 26.07 & -.216 & {$[-.262,-.169]$} & 0.009 & 85.75 & NA & REF \\
\hline Unpublished & 28 & 55 & 26.12 & -.217 & {$[-.266,-.168]$} & 0.018 & 89.62 & .904 & \\
\hline
\end{tabular}

\section{Study type}

$\begin{array}{llllllllll}\text { Repeated- } & 11 & 49 & 9.25 & -.155 & {[-.230,-.077]} & 0.013 & 68.92 & .070\end{array}$

measured

study

$\begin{array}{llllllllll}\text { Cross-sectional } & 55 & 93 & 50.82 & -.222 & {[-.254,-.189]} & 0.011 & 88.59 & \text { NA } & \text { REF }\end{array}$

\section{Loneliness scale}

$\begin{array}{llllllllll}\text { DJG-LS } & 6 & 14 & 4.97 & -.146 & {[-.289, .003]} & 0.018 & 86.16 & .097\end{array}$

$\begin{array}{llllllllll}\text { Other } & 12 & 22 & 10.31 & -.143 & {[-.200,-.085]} & 0.006 & 86.84 & .003\end{array}$

$\begin{array}{llllllllll}\text { UCLA } & 39 & 105 & 34.46 & -.258 & {[-.293,-.222]} & 0.010 & 82.37 & \text { NA } & \text { REF }\end{array}$

\section{Loneliness}

dimension

Overall

$43 \quad 108 \quad 39.05 \quad-.249 \quad[-.285,-.212] \quad 0.013 \quad 89.78$

NA

REF loneliness 
$\begin{array}{llllllllll}\text { Social } & 8 & 10 & 6.71 & -.169 & {[-.283,-.050]} & 0.010 & 87.14 & .275\end{array}$

loneliness

$\begin{array}{llllllllll}\text { Emotional } & 9 & 13 & 7.57 & -.167 & {[-.244,-.089]} & 0.006 & 79.97 & .113\end{array}$

loneliness

$\begin{array}{llllllllll}\text { Reliability of } & 28 & 53 & 3.65 & -.352 & {[-.912, .668]} & 0.014 & 82.14 & .422\end{array}$

loneliness

measure $^{\mathrm{a}}$

$\begin{array}{llllllllll}\text { Reliability of } & 29 & 67 & 9.56 & .220 & {[-.400, .702]} & 0.011 & 3.40 & .457\end{array}$

personality

measure

Note. $j=$ number of studies, $k=$ number of effect sizes, $d f=$ degrees of freedom, ES $=$ effect size (for categorical moderators, we report estimated mean correlation coefficients corrected for measurement error in the respective subset; for continuous moderators, we report regression coefficients out of the mixed effects RVE meta-regressions), $95 \% \mathrm{CI}=95 \%$ confidence interval, $p$-values indicate whether one category differed from the reference category or whether a continuous moderator reached significance, $\mathrm{REF}=$ reference category . ${ }^{a}$ Corresponding $p$-values should not be trusted due to small degrees of freedom $(d f<4$; Tipton, 2015). 
Table 7 Moderator Analyses for the Meta-Analyses on the Bivariate Relations Between

Loneliness and Neuroticism

\begin{tabular}{|c|c|c|c|c|c|c|c|c|c|}
\hline Moderator level & $j$ & $k$ & $d f$ & $\mathrm{ES}$ & $95 \% \mathrm{CI}$ & $\tau^{2}$ & $I^{2}$ & $p$-value & $\begin{array}{l}\text { Reference } \\
\text { category }\end{array}$ \\
\hline Age & 79 & 151 & 14.69 & .001 & {$[-.002, .004]$} & 0.086 & 98.06 & .340 & \\
\hline \% men & 90 & 154 & 20.63 & .001 & {$[-.001, .004]$} & 0.098 & 98.08 & .219 & \\
\hline Publication year & 93 & 197 & 22.24 & -.005 & {$[-.009, .001]$} & 0.075 & 97.88 & .020 & \\
\hline \multicolumn{10}{|l|}{ Publishing status } \\
\hline Published & 73 & 171 & 71.69 & .407 & {$[.355, .456]$} & 0.099 & 98.26 & NA & REF \\
\hline Unpublished & 29 & 56 & 27.70 & .371 & {$[.308, .431]$} & 0.041 & 95.37 & .232 & \\
\hline
\end{tabular}

Study type

$\begin{array}{llllllllll}\text { Repeated- } & 12 & 69 & 9.35 & .316 & {[.269, .360} & 0.006 & 49.08 & .023\end{array}$

measured study

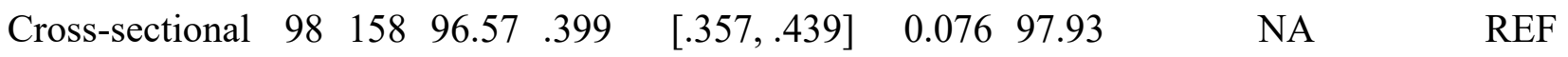

Loneliness scale

$\begin{array}{lllllllll}\text { DJG-LS } & 8 & 17 & 6.99 & .278 & {[.134, .410]} & 0.033 & 92.88 & .023\end{array}$

$\begin{array}{lllllllll}\text { Other } & 21 & 42 & 19.93 & .265 & {[.185, .342]} & 0.06 & 98.65 & .001\end{array}$

$\begin{array}{llllllllll}\text { UCLA } & 73 & 167 & 71.02 & .446 & {[.399, .490]} & 0.047 & 94.72 & \text { NA } & \text { REF }\end{array}$

\section{Loneliness}

dimension

$\begin{array}{lllllllllll}\text { Overall } & 82 & 178 & 80.58 & .421 & {[.376, .465]} & 0.088 & 98.17 & \text { NA } & \text { REF }\end{array}$

loneliness

$\begin{array}{llllllllll}\text { Social } & 13 & 16 & 11.64 & .287 & {[.186, .381]} & 0.017 & 89.68 & .006\end{array}$ 
loneliness

$\begin{array}{llllllllll}\text { Emotional } & 14 & 19 & 12.94 & .359 & {[.231, .474]} & 0.039 & 95.32 & .701\end{array}$

loneliness

$\begin{array}{llllllllll}\text { Other } & 7 & 13 & 5.94 & .268 & {[.173, .358]} & 0.027 & 87.81 & .013\end{array}$

\section{Personality}

framework

Five Factor

$\begin{array}{lllllll}69 & 180 & 66.74 & .407 & {[.359, .453]} & 0.036 & 95.60\end{array}$

NA

REF

Model

Three Factor

$\begin{array}{lllll}23 & 35 & 21.98 & .394 & {[.315, .468]}\end{array}$

0.19398 .88

.734

Model

Other

$\begin{array}{llll}7 & 12 & 6.00 & .230\end{array}$

$[-.084, .502] \quad 0.158 \quad 97.93$

.167

Reliability of

$\begin{array}{lllllll}61 & 123 & 15.66 & .506 & {[-.668, .958]} & 0.068 & 95.39\end{array}$

\section{loneliness}

measure

$\left.\begin{array}{lllllllllll}\text { Reliability of } & & 53 & 103 & 9.21 & .567 & {[-.374, .933}\end{array}\right] \quad 0.054 \quad 95.80 \quad .194$

personality

\section{measure}

Note. $j=$ number of studies, $k=$ number of effect sizes, $d f=$ degrees of freedom, ES = effect size (for categorical moderators, we report estimated mean correlation coefficients corrected for measurement error in the respective subset; for continuous moderators, we report regression coefficients out of the mixed effects RVE meta-regressions), 95\% CI $=95 \%$ confidence interval, $p$-values indicate whether one category differed from the reference category or whether a continuous moderator reached significance, $\mathrm{REF}=$ reference category. 
Table 8 Moderator Analyses for the Meta-Analyses on the Bivariate Relations Between Loneliness and Openness

\begin{tabular}{|c|c|c|c|c|c|c|c|c|c|}
\hline Moderator level & $j$ & $k$ & $d f$ & $\mathrm{ES}$ & $95 \% \mathrm{CI}$ & $\tau^{2}$ & $I^{2}$ & $p$-value & $\begin{array}{l}\text { Reference } \\
\text { category }\end{array}$ \\
\hline Age & 52 & 113 & 7.46 & -.002 & {$[-.003,-.000]$} & 0.017 & 90.31 & .023 & \\
\hline \% men & 52 & 97 & 11.54 & -.001 & {$[-.003, .001]$} & 0.014 & 87.11 & .312 & \\
\hline Publication year & 52 & 111 & 4.78 & .000 & {$[-.016, .016]$} & 0.010 & 86.64 & .963 & \\
\hline \multicolumn{10}{|l|}{ Publishing status } \\
\hline Published & 33 & 87 & 29.10 & -.141 & {$[-.181,-.101]$} & 0.013 & 85.77 & NA & REF \\
\hline Unpublished & 27 & 54 & 24.03 & -.094 & {$[-.134,-.052]$} & 0.009 & 87.62 & .096 & \\
\hline \multicolumn{10}{|l|}{ Study type } \\
\hline Repeated- & 11 & 48 & 8.50 & -.100 & {$[-.175,-.023]$} & 0.008 & 55.72 & .312 & \\
\hline \multicolumn{10}{|l|}{ measured } \\
\hline \multicolumn{10}{|l|}{ study } \\
\hline Cross-sectional & 57 & 93 & 52.34 & -.125 & {$[-.153,-.096]$} & 0.012 & 89.22 & NA & REF \\
\hline \multicolumn{10}{|l|}{ Loneliness scale } \\
\hline DJG-LS & 6 & 12 & 4.84 & -.099 & {$[-.169,-.029]$} & 0.006 & 67.45 & .310 & \\
\hline Other & 11 & 21 & 9.50 & -.081 & {$[-.138,-.023]$} & 0.006 & 88.46 & .123 & \\
\hline UCLA & 42 & 107 & 37.19 & -.134 & {$[-.172,-.095]$} & 0.013 & 85.63 & NA & REF \\
\hline \multicolumn{10}{|l|}{ Loneliness } \\
\hline
\end{tabular}


$\begin{array}{llllllllll}\text { Overall } & 43 & 105 & 38.67 & -.128 & {[-.165,-.090]} & 0.015 & 91.44 & .197\end{array}$

loneliness

Social

$9 \quad 11$

$7.58 \quad-.180 \quad[-.272,-.085]$

$0.013 \quad 87.93$

NA

REF

loneliness

Emotional

1014

8.57

$-.11$

$3[-.182,-.044] 0.007$

80.20

.090

loneliness

$\begin{array}{llllllllll}\text { Reliability of } & 28 & 53 & 5.03 & .348 & {[-.048, .650]} & 0.014 & 81.56 & .073\end{array}$

loneliness

measure

$\begin{array}{llllllllll}\text { Reliability of } & 28 & 65 & 9.11 & -.170 & {[-.541, .257]} & 0.016 & 86.43 & .396\end{array}$

personality

measure

Note. $j=$ number of studies, $k=$ number of effect sizes, $d f=$ degrees of freedom, ES $=$ effect size (for categorical moderators, we report estimated mean correlation coefficients corrected for measurement error in the respective subset; for continuous moderators, we report regression coefficients out of the mixed effects RVE meta-regressions), $95 \% \mathrm{CI}=95 \%$ confidence interval, $p$-values indicate whether one category differed from the reference category or whether a continuous moderator reached significance, $\mathrm{REF}=$ reference category . 
Table 9 Summary of the Main Moderators on the Relations Between Personality Traits and Loneliness

\begin{tabular}{|c|c|c|c|c|c|c|}
\hline & \multicolumn{6}{|c|}{ Moderators } \\
\hline & $\mathrm{Age}^{\mathrm{a}}$ & $\begin{array}{l}\text { Year of } \\
\text { publication }^{\text {a }}\end{array}$ & $\begin{array}{l}\text { Loneliness } \\
\text { dimension }^{\text {b }}\end{array}$ & $\begin{array}{l}\text { Loneliness } \\
\text { scale }^{b}\end{array}$ & Study type ${ }^{b}$ & $\begin{array}{l}\text { Publication } \\
\text { status }^{\text {b }}\end{array}$ \\
\hline Extraversion & - & - & $\begin{array}{l}\text { relational }> \\
\text { intimate } \\
\text { overall > } \\
\text { intimate }\end{array}$ & $\begin{array}{l}\text { UCLA> } \\
\text { other } \\
\text { UCLA> } \\
\text { DJG-LS }\end{array}$ & & \\
\hline Agreeableness & & & & $\begin{array}{l}\text { UCLA> } \\
\text { other } \\
\text { UCLA > } \\
\text { DJG-LS }\end{array}$ & & $\begin{array}{l}\text { published }> \\
\text { unpublished }\end{array}$ \\
\hline Conscientiousness & & & & $\begin{array}{l}\text { UCLA > } \\
\text { other }\end{array}$ & & \\
\hline Neuroticism & & - & $\begin{array}{l}\text { overall > } \\
\text { relational }\end{array}$ & $\begin{array}{l}\text { UCLA > } \\
\text { other } \\
\text { UCLA > } \\
\text { DJG-LS }\end{array}$ & $\begin{array}{l}\text { cross- } \\
\text { sectional > } \\
\text { repeatedly } \\
\text { measured }\end{array}$ & \\
\hline Openness & + & & & & & \\
\hline $\begin{array}{l}\text { Note. }{ }^{\text {a These colum }} \\
\text { loneliness and the r } \\
\text { increases. - indicate } \\
\text { for this personality } \\
\text { differences between } \\
\text { the relation between } \\
\text { category in front of } \\
\text { statistically signific }\end{array}$ & $\begin{array}{l}\text { mmarize } \\
\text { tive pers } \\
t \text { the rela } \\
\text { he contin } \\
\text { subsets } t \\
\text { onality a } \\
\text { ign. Emp }\end{array}$ & $\begin{array}{l}\text { ction of the eff } \\
\text { trait. + indicate } \\
\text { s weaker, when } \\
\text { loderator was n } \\
\text { esent different } \\
\text { liness was sign } \\
\text { indicate that fo }\end{array}$ & $\begin{array}{l}\text { tof the contint } \\
\text { that the relation } \\
\text { he continuous } 1 \\
\text { statistically sig } \\
\text { oderator categc } \\
\text { cantly stronger } \\
\text { this personality }\end{array}$ & $\begin{array}{l}\text { lous moderator } \\
\text { gets stronger, } \\
\text { noderator incre } \\
\text { nificant. bThes } \\
\text { ries. The "gree } \\
\text { in the subset } \mathrm{t} \\
\text { trait the categ }\end{array}$ & $\begin{array}{l}\text { ariables on the } \\
\text { hen the continu } \\
\text { es. Empty cells } \\
\text { columns summ } \\
\text { r-than" sign ( }> \\
\text { t represents the } \\
\text { cal moderator }\end{array}$ & $\begin{array}{l}\text { lation betweer } \\
\text { us moderator } \\
\text { indicate that } \\
\text { ize the } \\
\text { indicates that } \\
\text { noderator } \\
\text { as not }\end{array}$ \\
\hline
\end{tabular}


Figure 1. Flow diagram for the study identification and inclusion process.

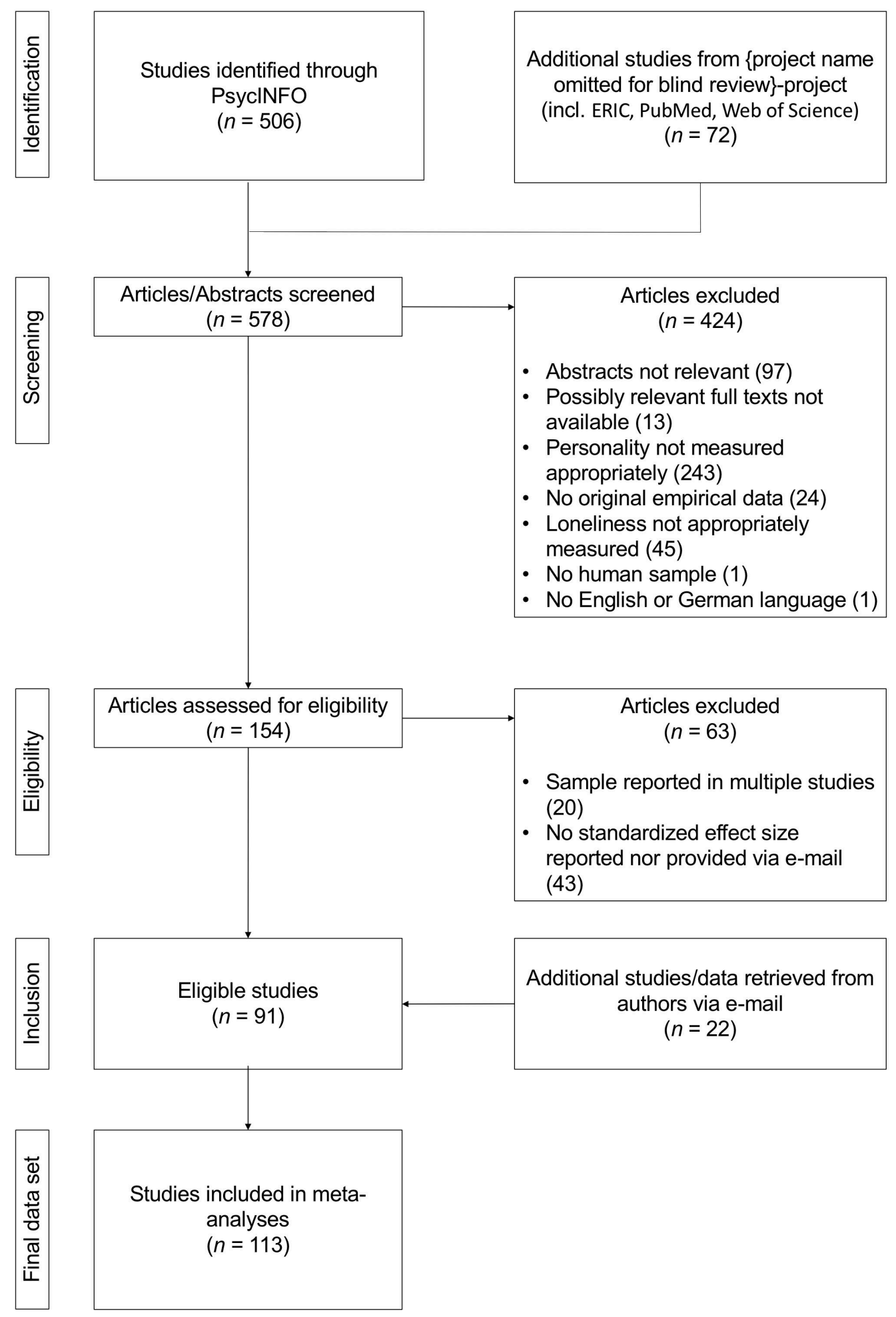


Figure 2. Contour-enhanced funnel plots for extraversion, agreeableness, conscientiousness, neuroticism, and openness at the study level.
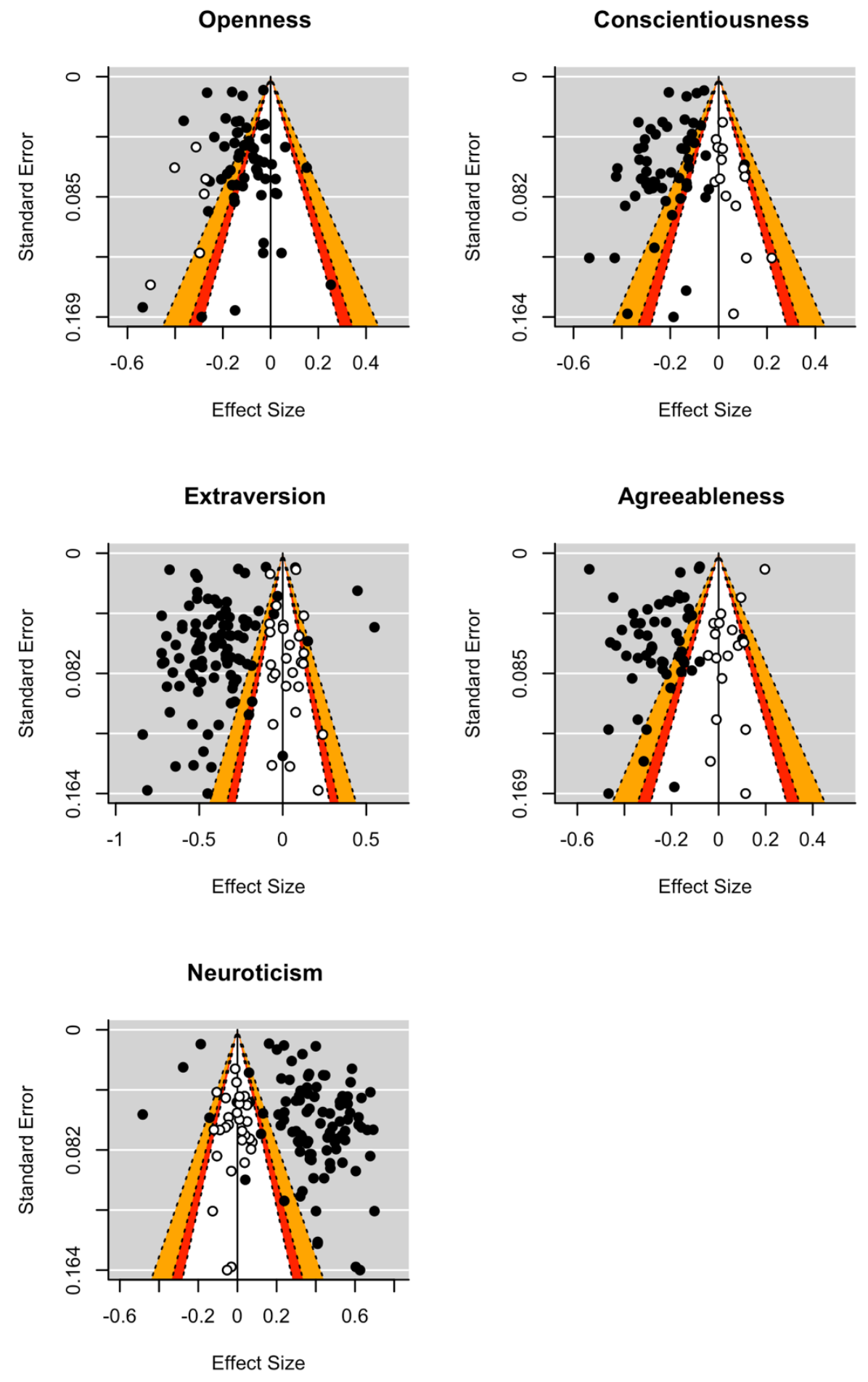
Note. Dark-colored points indicate aggregated estimates that were included in the present metaanalysis. White points indicate estimates that have to be imputed to achieve symmetry using the trim-and-fill approach (Duval \& Tweedie, 2000). Contour lines allow the consideration of the statistical significance of study estimates. White background color indicates $p>.10$, red background color indicates $.05<p<.10$, orange background color indicates $.001<p<.05$, and grey background color indicates $p<.001$. 


\section{Supplementary Material}

Table S1

Meta-Analytic Intercorrelations Among the Big Five Personality Traits Estimated With MASEM

\begin{tabular}{cccc}
\hline Big Five pairing & $j$ & $r$ & $95 \%$ CI \\
\hline E-A & 59 & .173 & {$[.134, .211]$} \\
E-C & 59 & .156 & {$[.122, .189]$} \\
E-N & 84 & -.204 & {$[-.256,-.153]$} \\
E-O & 58 & .223 & {$[.177, .270]$} \\
A-C & 58 & .221 & {$[.190, .252]$} \\
A-N & 58 & -.216 & {$[-.265,-.166]$} \\
A-O & 55 & .167 & {$[.129, .205]$} \\
C-N & 60 & -.206 & {$[-.257,-.156]$} \\
C-O & 56 & .106 & {$[.069, .143]$} \\
N-O & 57 & -.076 & {$[-.114,-.038]$} \\
& & & \\
\hline
\end{tabular}

Note. MASEM = Meta-Analytic Structural Equation Modeling, $\mathrm{j}=$ number of studies, $r=$ metaanalytic correlation, $95 \% \mathrm{CI}=95 \%$ confidence interval, $\mathrm{E}=$ extraversion; $\mathrm{A}=$ agreeableness; $\mathrm{C}$ $=$ conscientiousness $; \mathrm{N}=$ neuroticism; $\mathrm{O}=$ openness. 
Table S2

Meta-Analytic Estimates of the Bivariate and Multivariate Relations Between Loneliness (measured with the UCLA Loneliness Scale) and Personality using MASEM

\begin{tabular}{|c|c|c|c|c|}
\hline \multirow[b]{3}{*}{ Personality trait } & \multicolumn{4}{|c|}{ Loneliness (UCLA Loneliness Scale) } \\
\hline & \multicolumn{2}{|c|}{ Bivariate } & \multicolumn{2}{|c|}{ Multivariate } \\
\hline & ES & $95 \% \mathrm{CI}$ & $\mathrm{ES}$ & $95 \% \mathrm{CI}$ \\
\hline Extraversion & -.412 & {$[-.455,-.369]$} & -.312 & {$[-.363,-.260]$} \\
\hline Agreeableness & -.280 & {$[-.312,-.248]$} & -.137 & {$[-.178,-.095]$} \\
\hline Conscientiousness & -.239 & {$[-.270,-.209]$} & -.096 & {$[-.135,-.057]$} \\
\hline Neuroticism & .409 & {$[.372, .447]$} & .292 & {$[.246, .338]$} \\
\hline Openness & -.122 & {$[-.155,-.089]$} & .001 & {$[-.039, .043]$} \\
\hline
\end{tabular}

Note. MASEM = Meta-Analytic Structural Equation Modeling, ES = meta-analytic effect size; $95 \% \mathrm{CI}=95 \%$ confidence interval. 
Table S3

Meta-Analytic Estimates of the Bivariate and Multivariate Relations Between Loneliness (measured with the DJG-LS) and Personality using MASEM

\begin{tabular}{|c|c|c|c|c|}
\hline \multirow[b]{3}{*}{ Personality trait } & \multicolumn{2}{|c|}{ Loneliness (DJG-LS) } & & \\
\hline & \multicolumn{2}{|c|}{ Bivariate } & \multicolumn{2}{|c|}{ Multivariate } \\
\hline & ES & $95 \% \mathrm{CI}$ & ES & $95 \% \mathrm{CI}$ \\
\hline Extraversion & -.287 & {$[-.330,-.244]$} & -.172 & {$[-.224,-.118]$} \\
\hline Agreeableness & -.192 & {$[-.250,-.133]$} & -.084 & {$[-.152,-.014]$} \\
\hline Conscientiousness & -.155 & {$[-.217,-.092]$} & -.048 & {$[-.116, .020]$} \\
\hline Neuroticism & .321 & {$[.261, .381]$} & .222 & {$[.152, .292]$} \\
\hline Openness & -.127 & {$[-.199,-.056]$} & -.076 & {$[-.155, .005]$} \\
\hline
\end{tabular}

Note. MASEM = Meta-Analytic Structural Equation Modeling, ES = meta-analytic effect size; $95 \% \mathrm{CI}=95 \%$ confidence interval. 


\section{Additional Information on the Interpretation of PET-PEESE}

The Egger's test reveals significant results if effect sizes out of studies with small sample size and low precision differ significantly from effect sizes of larger studies with higher precision, indicating the presence of publication bias. The use of mixed effects models, trim-andfill in general, and aggregation at the study level is not optimal (Carter, Schönbrodt, Gervais, \& Hilgard, 2019), yet there is no alternative solution accepted in the field to correct for publication bias in RVE meta-analyses. Therefore, we additionally followed a procedure suggested by Bediou et al. (2018) and applied PET-PEESE (Stanley \& Doucouliagos, 2014) using the RVE approach. In this meta-regression model, the (Z-transformed) effect size is predicted by the standard errors (PET) or the variance (PEESE) of the (Z-transformed) estimates. In a model in which the effect size is predicted by its standard error, analogous to the Egger's regression test described above, a slope coefficient that significantly differs from zero indicates asymmetry and the presence of small-study effects (Stanley \& Doucouliagos, 2014). PET stands for the Precision Effect Test (Sterne \& Egger, 2005), whereas PEESE stands for the Precision-Effect Estimate with Standard Error (Stanley \& Doucouliagos, 2014). PET-PEESE is interpreted depending on the statistical significance of the intercept in the PET model. The intercept of the PET model is interpreted as adjusted estimate if the PET-intercept is non-significant. If the PET-intercept is significant, the intercept of the PEESE model is interpreted as adjusted estimate. For a full description of the PET-PEESE logic see Stanley and Doucouliagos (2014). Note that PETPEESE does have some shortcomings especially when there is large heterogeneity between studies. However, PET-PEESE still outperforms other publication bias analysis approaches under the same conditions (Stanley, 2017). 


\section{Additional Information on the Interrater Agreement of two coders}

The percentage of agreement (calculated as $100 *$ (number of consistently coded studies / number of all double coded studies)) between both coders was 96.5\% in Step 1 for study inclusion. In Step 2, the percentage of interrater agreement was 93\% for effect sizes regarding the associations between loneliness and the personality traits and ranged from $84 \%-100 \%$ for moderators of these associations.

\section{Full Moderator Results}

Please find the main moderator results in the main article entitled "Loneliness and the Big Five Personality Traits: A Meta-Analysis". Below we present the full moderator results separately for each personality trait.

\section{Moderation Analysis and Robustness Checks for the Relation Between Extraversion}

\section{and Loneliness}

The negative relation between extraversion and loneliness was moderated by age such that the relation got slightly weaker (i.e., less negative) with age $(b=.002,95 \% \mathrm{CI}$ $[.0001, .004])$. This result confirms our preregistered hypothesis regarding age. Studies using the UCLA Loneliness Scale revealed the strongest association with extraversion $\left(r^{+}=-.441,95 \%\right.$ CI $[-.490,-.389])$ compared to studies using the DJG-LS $\left(r^{+}=-.188,95 \%\right.$ CI $\left.[-.348,-.018]\right)$ or other scales measuring loneliness $\left(r^{+}=-.329,95 \%\right.$ CI $\left.[-.421,-.240]\right)$. Additionally, the relation between extraversion and loneliness was weaker for intimate loneliness $\left(r^{+}=-.232,95 \% \mathrm{CI}\right.$ $[-.344,-.114])$ than for the reference category of overall loneliness $\left(r^{+}=-.431,95 \%\right.$ CI $[-.478$, -.380]). When switching the reference category to relational loneliness, intimate loneliness was also weaker related to extraversion than relational loneliness $\left(r^{+}=-.398,95 \%\right.$ CI [-.528, -.250$\left.]\right)$. The association between extraversion and loneliness was robust across study type, measurement 
order, and the underlying personality framework (Big Three vs. Big Five vs. Other).

Unexpectedly, publication year was a significant moderator of the relation between extraversion and loneliness such that the relation between both constructs got slightly weaker over time $(b$ $=.005,95 \% \mathrm{CI}[.001, .009])$. Neither the reliability of the loneliness measure nor the reliability of the personality measure moderated the relation between extraversion and loneliness.

\section{Moderation Analysis and Robustness Checks for the Relation Between}

\section{Agreeableness and Loneliness}

The relation between agreeableness and loneliness was not significantly moderated by the mean age of the sample. However, the relation between agreeableness and loneliness was the only one that was significantly moderated by the publishing status of the included results. The relation between agreeableness and loneliness was stronger in studies published in a peerreviewed journal $\left(r^{+}=-.309,95 \%\right.$ CI $\left.[-.355,-.261]\right)$ than for unpublished studies $\left(r^{+}=-.226\right.$, 95\% CI [-.279, -.171]). Again, studies using the UCLA Loneliness Scale revealed a significantly stronger association with agreeableness $\left(r^{+}=-.302,95 \%\right.$ CI $\left.[-.342,-.260]\right)$ than studies using the DJG-LS $\left(r^{+}=-.157,95 \%\right.$ CI $\left.[-.300,-.006]\right)$ or other loneliness scales $\left(r^{+}=-.184,95 \%\right.$ CI [-.236, -.130]). The relation between agreeableness and loneliness was moderated by the loneliness dimension, such that agreeableness was more strongly associated with overall loneliness (reference category; $r^{+}=-.287,95 \%$ CI $\left.[-.328,-.246]\right)$ than with intimate loneliness $\left(r^{+}=-.147\right.$, $95 \%$ CI $[-.213,-.080])$. When switching the reference category to relational loneliness $\left(r^{+}=\right.$ $-.221,95 \%$ CI [-.347, -.087]), intimate loneliness did not significantly differ from this reference category. The results were robust across different study types (cross-sectional vs. repeatedmeasured studies). Additionally, neither publication year nor the reliability of the loneliness 
measure and the reliability of the personality measure significantly moderated the relation between agreeableness and loneliness.

\section{Moderation Analysis and Robustness Checks for the Relation Between}

\section{Conscientiousness and Loneliness}

The relation between conscientiousness and loneliness was not significantly moderated by the mean age of the sample. Studies that measured loneliness using the UCLA Loneliness Scale $\left(r^{+}=-.258,95 \%\right.$ CI [-.293, -.222]) revealed significantly higher correlations with conscientiousness than studies using scales that could not be definitely assigned to one of our scale categories (e.g., single item measures of loneliness; $r^{+}=-.143,95 \%$ CI [-.200, -.085]). However, studies using the DJG-LS $\left(r^{+}=-.146,95 \%\right.$ CI $\left.[-.289, .003]\right)$ did not significantly differ from studies using the UCLA Loneliness Scale. The relation between conscientiousness and loneliness was stronger in studies that measured both constructs simultaneously (which are identical to the cross-sectional studies; $r^{+}=-.222,95 \%$ CI $\left.[-.254,-.189]\right)$ than in studies that measured personality first and loneliness at least one day later $\left(r^{+}=-.101,95 \%\right.$ CI [-.184, -.016]). Unfortunately, the number of studies measuring loneliness first was too small $(d f<4)$ to test this moderator category. Other than that, the relation between conscientiousness and loneliness was robust across different study types and different loneliness dimensions. Additionally, neither publication year nor the reliability of the loneliness measure or the personality measure were significant moderators in this meta-analytic model.

\section{Moderation Analysis and Robustness Checks for the Relation Between Neuroticism}

\section{and Loneliness}

Again, the relation between neuroticism and loneliness was not significantly moderated by the mean age of the sample. Studies that used the UCLA Loneliness Scale revealed 
a higher correlation between loneliness and neuroticism $\left(r^{+}=.446,95 \%\right.$ CI $\left.[.399, .490]\right)$ than studies that used the DJG-LS $\left(r^{+}=.278,95 \%\right.$ CI $\left.[.134, .410]\right)$ or other loneliness scales $\left(r^{+}\right.$ $=.265,95 \% \mathrm{CI}[.185, .342])$. The relation between neuroticism and loneliness was stronger for measures assessing overall loneliness (reference category; $r^{+}=.421,95 \% \mathrm{CI}[.376, .465]$ ) than for measures assessing relational loneliness $\left(r^{+}=.287,95 \%\right.$ CI $\left.[.186, .381]\right)$ or for other measures that could not definitely assigned as "overall", "relational loneliness" or "intimate loneliness" and were therefore coded as "other" $\left(r^{+}=.268,95 \%\right.$ CI $\left.[.173, .358]\right)$. When switching the reference category to intimate loneliness, neither relational loneliness, overall loneliness, nor other loneliness dimensions differed significantly from this reference category. The relation was stronger in cross-sectional studies $\left(r^{+}=.399,95 \%\right.$ CI $\left.[.357, .439]\right)$ than in repeated-measured studies $\left(r^{+}=.316,95 \%\right.$ CI $\left.[.269, .360]\right)$. Compared to the cross-sectional studies where neuroticism and loneliness were measured simultaneously, the relation for studies measuring personality first was weaker $\left(r^{+}=.299,95 \%\right.$ CI $\left.[.243, .353]\right)$. Unfortunately, the number of studies where loneliness was measured first was too low $(d f<4)$ to allow analyzing this association. The result was robust across different personality frameworks and was not significantly moderated by the reliability of the loneliness or the personality measure. However, unexpectedly, publication year moderated the relation between neuroticism and loneliness significantly, indicating that the relation got slightly weaker over time $(b=-.005,95 \%$ CI [-.009, $-.001])$

\section{Moderation Analysis and Robustness Checks for the Relation Between Openness}

\section{and Loneliness}

Unexpectedly, the negative relation between openness and loneliness was significantly moderated by age such that the relation got stronger (i.e., more negative) with 
linearly increasing age $(b=-.002,95 \%$ CI [-.003, -.0003]). All other investigated moderator variables did not reach significance, indicating that our results were relatively robust across different demographic variables, different study characteristics, and across different types of loneliness measurements.

\section{References}

Bediou, B., Adams, D. M., Mayer, R. E., Tipton, E., Green, C. S., \& Bavelier, D. (2018). Metaanalysis of action video game impact on perceptual, attentional, and cognitive skills. Psychological Bulletin, 144(1), 77-110. https://doi.org/10.1037/bul0000130

Carter, E. C., Schönbrodt, F. D., Gervais, W. M., \& Hilgard, J. (2019). Correcting for bias in psychology: A comparison of meta-analytic methods. Advances in Methods and Practices in Psychological Science, 2(2), 115-144. https://doi.org/10.1177/2515245919847196

Stanley, T. D. (2017). Limitations of PET-PEESE and other meta-analysis methods. Social Psychological and Personality Science, 8(5), 581-591. https://doi.org/10.1177/1948550617693062

Stanley, T. D., \& Doucouliagos, H. (2014). Meta-regression approximations to reduce publication selection bias. Research Synthesis Methods, 5(1), 60-78. https://doi.org/10.1002/jrsm.1095

Sterne, J. A. C., \& Egger, M. (2005). Regression methods to detect publication and other bias in meta-analysis. In H. R. Rothstein, J. A. Sutton, \& M. Borenstein (Eds.), Publication bias in meta-analysis -Prevention, assessment and adjustments (pp. 99-110). Sussex, UK: Wiley. https://doi.org/10.1002/0470870168.ch6 